NBER WORKING PAPER SERIES

\title{
AGE VARIATIONS IN WORKERS' VALUE OF STATISTICAL LIFE
}

\author{
Joseph E. Aldy \\ W. Kip Viscusi \\ Working Paper 10199 \\ http://www.nber.org/papers/w10199 \\ NATIONAL BUREAU OF ECONOMIC RESEARCH \\ 1050 Massachusetts Avenue \\ Cambridge, MA 02138 \\ December 2003
}

The views expressed herein are those of the authors and not necessarily those of the National Bureau of Economic Research.

(C)2003 by Joseph E. Aldy and W. Kip Viscusi. All rights reserved. Short sections of text, not to exceed two paragraphs, may be quoted without explicit permission provided that full credit, including (C notice, is given to the source. 
Age Variations in Workers' Value of Statistical Life

Joseph E. Aldy and W. Kip Viscusi

NBER Working Paper No. 10199

December 2003

JEL No. J17, I12

\section{$\underline{\text { ABSTRACT }}$}

This paper develops a life-cycle model in which workers choose both consumption levels and job fatality risks, implying that the effect of age on the value of life is ambiguous. The empirical analysis of this relationship uses novel, age-dependent fatal and nonfatal risk variables. Workers' value of statistical life exhibits an inverted U-shaped relationship over workers' life cycle based on hedonic wage model estimates, age-specific hedonic wage estimates, and a minimum distance estimator. The value of statistical life for a 60 -year old ranges from $\$ 2.5$ million to $\$ 3.0$ million - less than half the value for 30 to 40 -year olds.

Joseph E. Aldy Department of Economics

Harvard University

Cambridge, MA 02138

aldy@fas.harvard.edu

W. Kip Viscusi

Harvard Law School

Hauser 302

Cambridge, MA 02138

and NBER

kip@law.harvard.edu 
The most strident controversy with respect to the value of life has been whether the benefit of reducing risks to the old are less than for younger age groups. In particular, should there be a so-called "senior discount" when assessing the value of reduced risks to life? While the U.S. Environmental Protection Agency (EPA) has traditionally employed a constant value of a statistical life to monetize mortality risk reductions irrespective of the age of the affected population, in 2003 the Agency conducted analyses of the Clear Skies initiative that included a "senior discount." generated a political firestorm and ultimately led to abandonment of any age adjustments in benefit values assigned by the Agency. ${ }^{3}$

Intuitively one might expect that older individuals may value reducing risks to their lives less because they have shorter remaining life expectancy. The commodity they are buying through risk reduction efforts is less than for younger people. Carrying this logic to its extreme, the value of a statistical life (VSL) would peak at birth and decline steadily thereafter.

Numerous theoretical studies have shown that the age variation in VSL is more complex. Increases in earnings capacity with education alter the wage one can earn, and changes in consumption levels and wealth over the life cycle influence risk-money tradeoffs in a complex manner. The recent study by Johansson (2002) concluded that the theoretical relationship between the VSL and age is ambiguous and could be positive, negative, or zero. Often theoretical studies, however, have imposed additional structure on the analysis, implying that there is either an inverted U-shaped relationship between the value of statistical life and age or that VSL decreases with age.

The simulations by Shepard and Zeckhauser (1984) show a steadily declining value of life if there are perfect annuity and insurance markets, while there is an inverted-U VSL-age 
relationship in an economy with no borrowing or insurance. Under illustrative restrictive assumptions, Johansson (1996) also finds that VSL probably follows an inverted U-shaped relationship. Rosen's (1988) simulation for ages 36 to 48, however, showed a steadily decreasing VSL with age. Likewise, Arthur (1981) and Cropper and Sussman (1988) present simulation results with VSL decreasing with age, as does Jones-Lee (1989) for the case in which consumption is constant over the life cycle. The VSL-age relationship is theoretically ambiguous in general, and depending on the additional structure that is imposed on the model or in numerical simulations, has been either always negative or characterized by an inverted-U shape in the published simulations in the literature.

Given that the strongest empirical evidence on VSLs in the United States is based on labor market data, one might expect studies of age variations in workers' VSLs to be instructive in resolving the theoretical ambiguity in the VSL-age relationship. Eight labor market studies have included an age-mortality risk interaction term in their hedonic wage analysis, which should be negative if older workers value risks to their lives less. Five of these studies estimated a negative and statistically significant coefficient on the age-mortality risk interaction term. ${ }^{4}$ While the $\log$ (wage) regression results for these studies imply that there is an inverted U-shaped relationship of VSL and age, the results often imply implausibly low VSL levels with negative VSL amounts at ages ranging from 42 to $60 .{ }^{5}$ Structural life cycle models of labor market and product market decisions adjust the standard hedonic wage models for life expectancy effects and assume a constant value per marginal year of life over the individual life cycle and usually across individuals as well. These studies indicate that the quantity of life does matter as they have yielded implicit rates of discount with respect to years of life ranging from 2 percent to a range of 11 percent -17 percent. $^{6}$ The failure of labor market evidence to resolve the age 
variation issue may stem in part from data limitations. All these labor market studies are hindered by use of fatality risk data that are based on industry averages rather than age-specific values, causing potential bias. If, for example, average industry fatality risks overstate the risks faced by older workers, the estimated implied VSL amounts will understate the wage-risk tradeoffs that are actually being made.

Contingent valuation (CV) studies have also investigated the effect of age on the willingness to pay for mortality risk reduction from hypothetical government programs. Several studies have employed quadratic age specifications that explicitly address the possibility of an inverted U-shaped relationship, including Jones-Lee et al. (1985), Johannesson et al. (1997), and Persson et al. (2001). All three analyses yielded statistically significant coefficients that implied an inverted-U for the value of a statistical life over the life cycle. The VSL in these studies tends to peak in the middle stage of life; for example, Johannesson et al. find that the VSL peaks at about age 40. Studies with more restrictive formulations in which age enters linearly have found a negative age-VSL relationship, as in Smith and Desvousges (1987), Corso et al. (2001), and Hammitt and Liu (2003). Finally, Krupnick et al. (2002) use age group indicator variables and find that VSL is fairly flat until age 70 , for which it is lower. ${ }^{7}$

This paper extends the previous literature in several respects. Because our focus is on risky labor market decisions, we incorporate job risk decisions into a life-cycle consumption model in Section I, deriving an expression for VSL in this context. In Section II, we develop the critical input to our empirical analysis - the first age-dependent measure of fatality risk and injury risk to be used in a hedonic labor market analysis. In Section III we develop several sets of empirical estimates of the VSL-age relationship: conventional hedonic wage equations, regressions with age-mortality risk interactions, wage equation estimates for specific age groups, 
and a minimum distance estimator that all indicate similar variations in VSL over the life cycle. In all of these empirical approaches, the VSL rises and then falls over the life cycle, with a peak in the 30 s, and a subsequent decline so that the VSL for workers in their early 60 s have values of about \$2.5-\$3 million. ${ }^{8}$ In Section IV, we calculate age-specific values of statistical life-years (VSLY) from our age-VSL profiles and find that after VSLYs peak at approximately the same age as VSLs peak, they decline monotonically with age. Section V concludes the paper.

\section{Wage-Risk Tradeoffs over the Life Cycle}

To motivate the empirical work, we provide a simple model of wage-risk tradeoffs in a one-period framework and a life-cycle setting. The implications of these simple models are not unambiguous with respect to the relationship between age and the VSL, although they do indicate variations in VSL by age. The life-cycle model can illustrate the influences that can generate an inverted U-shaped relationship between VSL and age.

As a starting point, and to clearly illustrate the implications of the life-cycle model on the wage-risk tradeoff estimated in the subsequent empirical work, we provide a one-period model involving the choice of the riskiness of one's job. ${ }^{9}$ Assume in the one-period model that only two states exist: alive and dead. We normalize the utility of the dead state to zero so that any bequests have some fixed value. The probability of dying on the job in the period is denoted by $p$. In this case, the worker's problem is to choose consumption and job fatality risk to maximize expected utility:

$$
\max _{c, p} E U=(1-p) u(c)
$$

subject to

$$
c=k+w(p)
$$


where

$p$ represents the probability of dying on the job,

$u(c)$ represents the utility of consumption, $c$, and $u^{\prime}(c) \geq 0, u^{\prime \prime}(c) \leq 0$,

$k$ represents (initial) assets, and

$w$ represents labor.

Solving for the optimal consumption and job risk yields this familiar expression for the wage-risk tradeoff:

$$
w_{p}=\frac{u}{(1-p) u_{c}}
$$

where

$w_{p}$ represents the derivative of the wage with respect to mortality risk $(p)$, and

$u_{c}$ represents the derivative of utility with respect to consumption $(c)$.

The value of $w_{p}$ is the VSL, or the change in the worker's wage with respect to occupational mortality risk. The VSL is given by the utility of consumption divided by the expected marginal utility of consumption. Because a fatal job accident leads to the loss of this period's utility as well as all future utility, one would expect there to be an analog of this result for life-cycle models. The standard approach in the life-cycle VSL literature employs a timeseparable utility function in one consumption good, integrated over the life-cycle subject to a discount function and a survival function, as in Shepard and Zeckhauser (1984), Rosen (1988), Johansson (1996, 2002), and Johannesson et al. (1997). These analyses modified the standard life-cycle model to reflect the expected utility of the rest of an individual's life conditional on the individual's current age. We extend the life-cycle approach to explicitly account for the 
influence of job fatality risk on the survival function and the worker's wage. Expected remaining lifetime utility can then be characterized by:

$$
E U(\tau)=\int_{\tau}^{\infty} u[c(t)] \sigma[t ; \tau, p(t)] e^{-r t} d t
$$

subject to

$$
\begin{aligned}
& \dot{k}(t)=r k(t)+w[t, p(t)]-c(t)+f(t), \\
& k(t) \geq 0, \\
& \lim _{t \rightarrow \infty} k(t) e^{-r t}=0,
\end{aligned}
$$

where

$e^{-r t}$ represents the discount function, $\sigma[t ; \tau, p(t)]$ represents the survival function, i.e., the probability of surviving to age $t$, given that the individual has reached age $\tau$, $r$ represents the return on assets, and $f(t)$ represents the net amount received through an actuarially fair annuity represented by the condition:

$$
\int_{0}^{\infty} e^{-r t} \sigma[t ; 0, p(t)] f(t) d t=0
$$

All other terms are simply their period t analogs to the single-period case. ${ }^{10}$

The worker's expected utility is represented in (4) as the sum of lifetime period utilities weighted by a discount factor and the probability that the worker will survive to that period conditional on the worker's current age. The worker maximizes this expected utility expression subject to the constraints: (5a) represents the dynamic budget constraint and it allows for the worker's assets to change over time based on capital income $(r k(t))$, labor income $(w[t, p(t)])$, 
consumption $(c(t))$, and net annuity receipts $(f(t))$; (5b) provides a no debt condition; and (5c) is the standard no Ponzi game condition. The actuarially fair annuity envisioned here is similar to that in Shepard and Zeckhauser's (1984) perfect markets case, and it allows for the worker to borrow against human capital during early years of life to provide for consumption smoothing.

The distinctive feature of our formulation is that wages for risky jobs enter the analysis, and the level of job fatality risk chosen by the worker is a choice variable in the model, as is the level of consumption in each period. Previous studies instead have focused simply on the lifecycle consumption choice without embedding in the model a compensating wage differential framework.

The present value Hamiltonian for this problem, conditional on having lived to age $\tau$, is given by:

$$
H(t)=u[c(t)] \sigma[t ; \tau, p(t)] e^{-r t}+\lambda(t)[r k(t)+w[t, p(t)]-c(t)+f(t)]
$$

where $\lambda(t)$ represents the present value costate variable. The first order conditions for the Hamiltonian are:

$$
\begin{aligned}
& \frac{\partial H}{\partial c}=u_{c} \sigma e^{-r t}-\lambda=0, \\
& \frac{\partial H}{\partial p}=u \sigma_{p} e^{-r t}+\lambda w_{p}=0
\end{aligned}
$$

and

$$
-\frac{\partial H}{\partial k}=\dot{\lambda} \rightarrow \dot{\lambda}=-r \lambda
$$

Substituting equation (7) into equation (8) and solving for $w_{p}$ yields:

$$
w_{p}=-\frac{u[c(t)]}{\left(\sigma / \sigma_{p}\right) u_{c}} .
$$


This condition should hold for every period. With the uncontroversial assumption that the probability of surviving to any given age is decreasing in the probability of dying on the job in the current year $\left(\sigma_{p}<0\right)$ and the probability of survival $(\sigma)$ is always positive, the ratio in the denominator is negative, so that the VSL is positive. Let $\pi=-\sigma / \sigma_{p}>0$, and the expression simplifies to:

$$
w_{p}=\frac{u[c(t)]}{\pi u_{c}},
$$

which is a clear analog to the single-period wage-risk tradeoff presented in equation (3). The implicit value of a statistical life revealed by workers in a life-cycle context is equal to the utility of consumption in that period divided by the marginal utility of consumption in that period, where the denominator is weighted by the term $\pi$. Whereas the denominator weight in the oneperiod model was simply the probability of survival in that period, $(1-p)$, for the life-cycle case the probability term $\pi$ in year $t$ reflects both the fatality risk of the job in year $t$ as well as the probability of survival to age $t$. While we have included actuarially fair annuities consistent with "perfect market" models in the literature (Shepard and Zeckhauser 1984, Johansson 2002), equation (11) is general to other characterizations of annuity markets. Our subsequent discussion will consider models with "perfect markets" (as described above) and "imperfect markets," similar to Shepard and Zeckhauser's Robinson Crusoe case, in which (5a) is rewritten without $f(t)$, the actuarially fair annuity. Such markets influence the VSL through their impact on the worker's optimal consumption and job risk fatality paths.

To see more generally how the value of a statistical life varies with age, we rearrange (8), differentiate with respect to time (time derivatives are denoted by a dot over the variables in question), and substitute into (9), yielding: 


$$
\frac{\dot{w}_{p}}{w_{p}}=\frac{\dot{u}}{u}+\frac{\dot{\sigma}_{p}}{\sigma_{p}}
$$

The percentage change over time in the compensating differential for job fatality risk is equal to the percentage change over time in utility and the percentage change over time in the change in the survival function with respect to job fatality risk. ${ }^{11}$ We make the uncontroversial assumptions that the compensating differential is always non-negative $\left(w_{p} \geq 0\right)$, utility is always non-negative $(u \geq 0)$, and the probability of surviving to any given age is decreasing in the probability of dying on the job in the current year $\left(\sigma_{p}<0\right)$. This expression holds irrespective of the assumption of actuarially fair annuity markets, although the assumption regarding these markets clearly impacts the change in utility over the life cycle.

The sign on equation (12) is ambiguous without imposing restrictions on the survival function and specifying the assumptions regarding annuity markets. If optimal consumption were to take an inverted-U path over the life cycle (consistent with an imperfect markets assumption), then utility would likewise follow a similar path. If we assume that $\dot{\sigma}_{p}$ is monotonic, which may not be a strong assumption considering that $\dot{\sigma}$ is monotonic, then the shape of the VSL over the life cycle would be driven by the inverted-U shape of the life cycle utility profile. In this case, if $\dot{\sigma}_{p}>0$, then the peak in the VSL would occur earlier in the life cycle than the peak in utility, and if $\dot{\sigma}_{p}<0$, then the VSL would peak later in the life cycle than the utility peak. If consumption were constant over the life cycle (consistent with perfect markets), then the change in the VSL over time would be driven by the change in the survival function as it changes with job fatality risk over time. If $\dot{\sigma}_{p}$ is not monotonic, then this expression becomes even more difficult to sign. 
This ambiguity is consistent with the life cycle model provided by Johansson (2002) and the simulation results based on the life cycle model in Shepard and Zeckhauser (1984). This theoretical ambiguity motivates our interest in investigating empirically how the value of a statistical life does vary over the life cycle.

\section{Job Risk Variations by Age}

To characterize the fatality risks faced by workers of different ages more precisely than is possible using average risk values by industry, we construct a risk measure conditional upon age and the worker's industry rather than using an industry basis alone, which is the norm for all previous studies of age variations in workers' VSL. The source of the fatality measures is the U.S. Bureau of Labor Statistics Census of Fatal Occupational Injuries (CFOI). Beginning in 1992, BLS utilized information from a wide variety of sources, including Occupational Safety and Health Administration reports, workers' compensation injury reports, death certificates, and medical examiner reports to develop a comprehensive database on every job-related fatality. For each death, there is information on the worker's age group and industry that we use in constructing the fatality risk variable. ${ }^{12}$

We structured the mortality risk cells in terms of 2-digit SIC industries and the age groups specified in the CFOI data: $16-19,20-24,25-34,35-44,45-54$, and 55-64. ${ }^{13}$ To construct the denominator for the mortality risk variable, we used the Current Population Survey Merged Outgoing Rotation Group files to estimate worker populations for each cell in the mortality data. The subsequent mortality risk is averaged over the 1992 to 1995 period to minimize any potential distortions associated with catastrophic mortality incidents in any one year and to have a better measure of the underlying risks for industry-age groups with infrequent deaths. Our 
injury risk measure also varies by age, and we constructed it in an identical manner for each 2digit industry and for each of the six age groups listed above. The injuries reported for that cell were those that were sufficiently severe to lead to at least one lost workday, or what is usually termed lost workday injuries. For both job risk variables, there are 632 distinct industry-age group risk values.

Injury and mortality risks are not constant across a worker's life cycle, making the age adjustment in the risk variables potentially important. Figure 1 depicts the injury risks of major 1-digit industries by age group. In almost every industry, the probability of a worker incurring a job-related injury decreases with that worker's age. In the case of manufacturing workers, for example, workers age 20-24 have an annual lost workday injury frequency rate of 3.5 per 100, as compared to 1.7 per 100 for workers age 55-64. This declining pattern of risk with age may reflect selection into safer jobs within industries by older and more experienced workers. Firms may place new hires, who are typically younger workers, in riskier jobs than more senior workers. As workers become more senior they often move into more supervisory roles for which the risks are lower. The injury risk-age relationship may also reflect the benefit of experience that enables older workers to self-protect and mitigate their exposure to accident risks.

In contrast to the lost workday injury risk data, however, mortality risks increase with age across industries as is evident in Figure 2. Mortality risks peak for either workers aged 55 to 64 or those older than 64 in all seven major industries presented in this figure. ${ }^{14}$ Whereas lost workday injury risks for manufacturing workers decline steadily with age, the annual fatality risk rate increases with age, as it is 2.65 per 100,000 for workers age $20-24$ and 4.62 per 100,000 for workers age 55-64. This positive relationship between job-related fatality risks and age is not the result of industry averages failing to reflect accurately the age-related differences within types of 
jobs. Even within occupations, the mortality risk peaks for either workers aged 55 to 64 or those older than 64, as shown in Figure 3. Our subsequent empirical analysis uses an industry-age breakdown of cells rather than occupation-industry-age because the more refined breakdown results in a large number of cells with zero fatalities. Indeed, using one-digit occupation/twodigit industry/age group breakdowns would lead to approximately 6,200 cells to capture an average of about 6,600 annual fatalities. Mortality risks also increase with age for different causes of the injury, such as gunshot wounds, asphyxiation, electrocution, intracranial injuries, burnings, drownings, etc. There is also a positive age-fatality risk relationship based on the type of injury event, such as transportation accidents, falls, fires and explosions, assaults, and exposure to harmful substances. From all three perspectives, job fatality risk is increasing with worker age.

While older workers are less likely to be injured on the job than younger workers, given that they are injured, they are much more likely to die from that job-related accident. This result may not be too surprising given that older workers are probably more vulnerable to serious injury from any particular incident. Moreover, accident rates off the job often reflect similar patterns, as there is an increase in deaths from falls, automobile accidents, and other risks for the most senior age groups. ${ }^{15}$ The age-specific divergence in injury and mortality risks reflected in our risk data will facilitate the estimation of wage premiums for both fatal and nonfatal risks, which few previous studies have been able to do.

\section{Methods and Results}

To assess empirically the VSL-age relationship, we have undertaken a variety of hedonic wage analyses with the job-related mortality and injury data described in the preceding section. 
We present the following series of results: (A) standard hedonic wage regressions, including the interaction of mortality risk and age; (B) separate age group subsample hedonic wage regressions; and (C) a minimum distance estimator based on a series of age-specific hedonic wage regressions in the first stage. For these statistical analyses, we have matched our constructed age-specific mortality and injury risk measures with the 1996 Current Population Survey Merged Outgoing Rotation Group data file. We have employed a number of screens in constructing our sample for analysis. The sample excludes agricultural workers and members of the armed forces. We have excluded workers younger than 18 and older than 62 , those with less than a 9th grade education, workers with an effective hourly labor income less than the 1996 minimum wage of $\$ 4.25$, and less than full-time workers, which we defined as 35 hours per week or more. Table 1 summarizes the descriptive statistics of the key variables in our data set. The lost workday injury frequency rate for the sample is 0.15 and the annual fatality rate is 4 per 100,000 , each of which is in line with national norms.

\section{A. Hedonic Wage Regressions with Age-Risk Interactions}

The standard hedonic wage model estimates the locus of tangencies between the market offer curve and workers' highest constant expected utility loci. The age variation in the wagemortality risk tradeoff simultaneously reflects age-related differences in preferences as well as age-related differences in the market offer curve. If older workers are more likely to be seriously injured than are younger workers because of age-related differences in safety-related productivity, then the market offer curve will reflect that, given that age is a readily monitorable attribute. Because workers' constant expected utility loci and firms' offer curves each may vary with age, there is no single hedonic market equilibrium. Rather, workers of different age will 
settle into distinct market equilibria as workers of different ages select points along the market opportunities locus that is pertinent to their age group. ${ }^{16}$

Conventional hedonic wage analyses of job risks regress the natural logarithm of the hourly wage or some comparable income measure on a set of worker and job characteristics, mortality risk, injury risk, and a measure of workers' compensation. ${ }^{17}$ Many studies, however, have been more parsimonious, omitting nonfatal injury risks and workers' compensation because of the difficulty of estimating statistically significant coefficients for three risk-related variables. In the case of the hedonic regressions that interact age with mortality risk, the specification takes the following form:

$$
\ln \left(w_{i}\right)=\alpha+H_{i}^{\prime} \beta+\gamma_{1} p_{i}+\gamma_{2} p_{i} \text { Age }_{i}+\gamma_{3} q_{i}+\gamma_{4} q_{i} W C_{i}+\varepsilon_{i},
$$

where

$w_{i}$ is the worker i's hourly after-tax wage rate,

$\alpha$ is a constant term,

$H$ is a vector of personal characteristic variables for worker i,

$p_{i}$ is the fatality risk associated with worker i's job,

$q_{i}$ is the nonfatal injury risk associated with worker i's job,

$W C_{i}$ is the workers' compensation replacement rate payable for a job injury suffered by

worker i, and

$\varepsilon_{i}$ is the random error reflecting unmeasured factors influencing worker i's wage rate.

We calculated the workers' compensation replacement rate on an individual worker basis taking into account state differences in benefits and the favorable tax status of these benefits. We use the benefit formulas for temporary total disability, which comprise about three-fourths of all 
claims, and have formulas similar to those for permanent partial disability. ${ }^{18}$ The terms $\alpha, \beta, \gamma_{1}$, $\gamma_{2}, \gamma_{3}$, and $\gamma_{4}$ represent parameters to be estimated.

As an initial step, we have used our age-specific mortality and injury risk data set in a standard hedonic wage regression without interacting age with the mortality risk variable, i.e., omitting the $p_{i} A g e_{i}$ term in the regression. This equation can serve both as a benchmark for the subsequent age-based VSL estimates and as a means for comparing estimates using age-specific mortality risk data to results with fatality risks not conditional upon age. Table 2, Column 1 presents the results from this ordinary least squares regression. All regressors are statistically significant at the 1 percent level with the exception of the Native American indicator variable.

The value of a statistical life is given by

$$
V S L=\hat{\gamma}_{1} * \bar{w} * 2,000 * 100,000{ }^{19}
$$

This equation normalizes the VSL to an annual basis by the assumption of a 2,000-hour workyear and by accounting for the units of the mortality risk variable. Evaluated at the sample mean wage, the coefficient on the mortality risk variable implies a sample mean value of a statistical life of $\$ 4.23$ million (1996\$), with a 95 percent confidence interval of $\$ 3.20$ to $\$ 5.28$ million. This value is within the range of VSLs from hedonic wage regression studies of the U.S. labor market reported in Viscusi and Aldy (2003) and is statistically indistinguishable from the VSL reported in Viscusi (2004) based on the 1997 CPS and a non-age based mortality risk measure. ${ }^{20}$

For all regression results, we report both White heteroskedasticity-corrected standard errors in parentheses as well as robust and clustered standard errors accounting for potential within-group correlation of residuals in brackets. Assigning individuals in our sample mortality and injury risk variables' values based on 2-digit industry and age group, and the workers' compensation replacement rate variable's values based on 2-digit industry, age group, and state 
may result in industry, age group, and/or state level correlation of residuals in the regressions. The reported within-group adjusted standard errors reflect a grouping of the observations based on 2-digit industry and state. We have also undertaken these regressions with group adjustments based on 2-digit industry, state, and age group. The standard errors yielded by this correction always fall within the range of the two sets of reported standard errors in this paper. While this within-group correlation correction generates larger standard errors and thus larger confidence intervals than those reported in Table 2, they do not change any of the qualitative determinations of statistical significance. Most studies in the hedonic wage literature have not accounted for this within-group correlation, and consequently may tend to overstate the significance of the risk premium estimates. ${ }^{21}$

To account for the influence of occupational injury insurance on the compensating differentials for occupational injuries and fatalities, we have included the expected workers' compensation replacement rate in all regression specifications. We calculated this variable for each individual based on the respondent's characteristics and state benefit formulas. The variable represents the interaction of a worker's injury rate and that worker's estimated workers' compensation wage replacement rate based on the worker's wage, state of residence, and estimated state and federal tax rates. The replacement rate variable accounts for the favorable tax status of workers' compensation benefits, which are comparable in tax terms to wages. Since the expected replacement rate is a function of a worker's wage, this variable could be endogenous in our regressions although tests for endogeneity were not conclusive. ${ }^{22}$ We have conducted two-stage least squares regressions including an instrumental variables estimate of the expected worker's compensation replacement rate. These specifications yield very similar 
coefficient estimates, estimated variances, and estimated VSLs to the OLS specifications as shown in Table 2.

Table 2, Columns 3 and 4 present the regression results for specifications that include the interaction of age and risk. As in the linear mortality risk regressions, all regressors are statistically significant at the 1 percent level except for the Native American indicator variable. The positive coefficient associated with the mortality risk variable and the negative coefficient on the interaction of age and mortality risk imply that the compensating differential for bearing mortality risk on the job should decrease with age, ceteris paribus. The wage, however, is not constant over the worker's life cycle, and the VSL derived from a semi-log model is a linear function of the wage rate. The estimated VSL implied by these regressions follows an invertedU shape. The risk-age interaction curve in Figure 4 illustrates the relationship between VSL and age based on these estimates. ${ }^{23}$ The VSL peaks at a value of $\$ 5.93$ million at age 29 , and remains positive until age 61. It should be noted, however, that this result might be a consequence of the limitations imposed by the constraining functional form of an age-risk interaction term.

While accounting for the interaction of mortality risk and age clearly influences the estimated VSL over the life cycle, it does not appear to influence the point estimate of the mean VSL for the sample. As the last row in Table 2 illustrates, estimates using the linear mortality risk formulation and the mortality risk plus age-risk interaction yield virtually identical VSL estimates by OLS and by 2SLS.

While these initial results accounting for age-specific mortality risks through both the construction of the mortality and injury risk variables and the specification of the hedonic wage regression suggest that the VSL varies substantially over the life cycle, a simple interaction of 
age and risk may be too rigid a characterization of the age-specific income-risk tradeoff. The implausible negative VSLs for individuals aged 61 and 62 years in our analysis and for earlier age groups in all previously published analyses especially cast doubt on this approach.

\section{B. Hedonic Wage Regressions with Age Group Subsamples}

The large CPS sample provides the opportunity to examine the wage-risk tradeoff with a number of age-specific subsamples. We have employed the same specifications as presented in columns (1) and (2) of Table 2, which do not include an age-fatality risk interaction, to estimate a hedonic wage model with the following age group subsamples: 18-24, 25-34, 35-44, 45-54, and 55-62. This formulation maintains the assumption that within-age categories job mortality risk has a linear impact on the natural logarithm of the wage, but it imposes less structure on the relationship between the compensating differential for mortality risk and age than did the interaction approach presented in columns (3) and (4) of Table 2. Unlike the earlier results, the estimated returns to mortality risk for an 18-year old will not influence the estimated returns for a 55-year old in the separate age group regressions.

Table 3 presents the results for the ordinary least squares regressions involving these five age group subsamples. ${ }^{24}$ The job mortality risk variable is statistically significant in all five regressions. The estimated VSLs for each age group are based on age-group-specific average wages and are presented in the last row of the table. As in the risk-age interaction results above, the age-group regressions reflect an inverted-U for the VSL-age relationship for 18-62 year-olds. Unlike the age-risk interaction results, the age-specific regressions in Table 3 reveal a peak in the VSL at an older age - in the 35-44 age group - as well as higher VSLs for the youngest and oldest age groups. This higher VSL for older workers may illustrate the limitations of the widely 
used risk-age interaction approach. The coefficient estimates for mortality risk and the interaction of risk and age are driven primarily by those aged $25-54$, which comprise more than 80 percent of our entire sample, and may produce a VSL function over age that may fit the denser part of the data well but not the VSLs for those at the ends of the age distribution of our sample.

To determine if these differences in VSLs presented in Table 3 are statistically significant, we employed the same variant of a Wald statistic presented in note 20. The VSL for the 18-24-year old age group is statistically different from the VSLs for the 25-34 and 35-44 year old age groups $\left(\mathrm{W}_{18-24,25-34}=6.76, \mathrm{~W}_{18-24,35-44}=7.08\right.$, and $\chi_{1}^{2}=6.63$ at the 1 percent level and $\chi_{1}^{2}=3.84$ at the 5 percent level), but cannot be distinguished statistically from the VSLs for the older two age groups. The VSL for the 25-34 age group is statistically different from the VSLs for the older two age groups $\left(\mathrm{W}_{25-34,45-54}=4.40, \mathrm{~W}_{25-34,55-62}=5.58\right)$, but cannot be distinguished from the VSL for the 35-44 year old age group. The VSL for the 35-44 age group is also statistically different from the VSLs for the older two age groups $\left(\mathrm{W}_{35-44,45-54}=4.94, \mathrm{~W}_{35-34,55-62}\right.$ $=6.13$ ). The VSLs for the two oldest age groups cannot be distinguished from each other. ${ }^{25}$ This more flexible approach of estimating VSLs by age group indicates that the VSL does vary with respect to age and takes an inverted-U shape. ${ }^{26}$

\section{Minimum Distance Estimator}

We have extended this age-specific regression analysis in subsection B through a twostage minimum distance estimator with smaller intervals of age. This approach allows us to infer information about the VSL with respect to age from regressions with smaller slices of the sample even though these regressions may individually provide imprecise estimates of the compensating 
differential for risk. If age-specific VSLs follow a systematic pattern over the life cycle, then we should be able to fit these to a function of age. Our minimum distance estimator implements this strategy. In the first stage, we estimate one-year and five-year age interval hedonic wage regressions and use the mortality risk coefficient estimates to construct age-specific VSL estimates. In the second stage, we estimate these VSLs as a function of a polynomial in age, and employ the inverse of a diagonal matrix of the variance estimates of these VSLs as a weight matrix based on Chamberlain's (1984) analysis of the minimum distance estimator and the choice of the inverse of the variance-covariance matrix as the optimal weight matrix. ${ }^{27}$

The minimum distance estimator solves the following:

$$
\min _{\theta \in \Theta}[V \hat{S} L-a(\theta)]^{\prime}[\hat{V}]^{-1}[V \hat{S} L-a(\theta)]
$$

where

$$
\hat{V}=\left[\begin{array}{ccc}
\operatorname{var}\left(V \hat{S} L_{1}\right) & 0 & 0 \\
0 & \ddots & 0 \\
0 & 0 & \operatorname{var}\left(V \hat{S} L_{N}\right)
\end{array}\right]
$$

$V \hat{S} L$ represents the VSLs estimated from the $\mathrm{N}$ age-specific hedonic wage regressions, and $a(\theta)$ represents a polynomial function in age. While the minimum distance approach typically involves estimating an initial stage of reduced form parameters to facilitate the estimation of a structural model in the second stage, we have chosen to impose as little structure as possible on the reduced form estimates by simply fitting the VSL estimates to polynomial functions in age.

For the first stage of the minimum distance estimator, we undertook the standard hedonic wage regressions for age-specific subsamples covering one- and five-year intervals from our 18 to 62 -years of age sample. The set of regressors in these subsample regressions is identical to the linear mortality risk regression specification used with the entire sample, with the exception of 
omitting the Age and $\mathrm{Age}^{2}$ variables in the one-year interval regressions. With the one-year interval subsamples, we estimated age-specific compensating differentials for mortality risk in 45 separate regressions. Likewise, we estimated age group-specific compensating differentials for mortality risk in 9 separate regressions with the five-year interval subsamples. For the one-year interval regressions, sample sizes range from 665 to 3,737 and $\mathrm{R}^{2} \mathrm{~s}$ range from 0.17 to 0.59 . For the five-year interval regressions, sample sizes range from 5,234 to 18,189 and $\mathrm{R}^{2} \mathrm{~s}$ range from 0.21 to 0.54 . For the 45 mortality risk coefficient estimates from the one-year interval regressions, 9 are statistically significant at the 1 percent level, 7 are significant at the 5 percent level, and another 4 are significant at the 10 percent level. For the 9 mortality risk coefficient estimates from the five-year interval regressions, 6 are significant at the 1 percent level, 2 are significant at the 5 percent level, and 1 is significant at the 10 percent level. ${ }^{28,29}$ For the second stage, we estimated the VSL using the mean wage for that age or five-year age interval. We specified $a(\theta)$ in a variety of analyses as a polynomial in age of order two to order six.

To illustrate this approach, Table 4 presents the first stage VSLs and second stage coefficient and variance estimates for the five-year interval with third-order polynomial in age estimator. ${ }^{30}$ The first stage results for the five-year interval approach are interesting in their own right, since they are all statistically significant and depict a clear inverted-U over the life cycle. The estimated coefficients were used to graph the VSL over the life cycle depicted in Figure 5, and the estimated variance-covariance matrix was used to fit the confidence intervals. While the third-order polynomial shows a slight increase in the VSL starting at about age 58, this increase is not statistically significant and is a consequence of the polynomial fitted to the data. Note that the point estimate for the 58-62 age group is smaller than the point estimate for the 53-57 age group in the first stage of the analysis. 
Figure 6 presents the fitted VSLs as a function of third-order polynomials in age with their 95 percent confidence intervals for the one-year interval analysis. For both the one-year and five-year interval approaches, the value of a statistical life takes an inverted-U shape over the life cycle. For the older workers in our sample, the confidence interval widens for both the oneyear and five-year interval periods. While these two interval periods vary in terms of their peak VSL and the VSLs for young workers, they both yield similar VSLs of approximately $\$ 2.5$ million for 62-year olds. This result is comparable to the subsample VSL estimate for the 58-62 age group in Table 4, and slightly less than the \$2.9 million VSL estimate for the 55-62 age group presented in Table 3.

Finally, we tested the two propositions that characterize current policy applications of the value of life: (1) the value of a statistical life is constant over the life cycle (as reflected in most Environmental Protection Agency benefit-cost analyses, including September 2003 revisions to its assessment of the Clear Skies initiative), and (2) the value of a statistical life is always decreasing with age (as reflected in the life-year approach used by the Food and Drug Administration and some of the Environmental Protection Agency's sensitivity analyses). To test the former hypothesis, we specified the age polynomial function as a constant and employed the overidentifying restrictions test presented in note 30 . For both the one-year and five-year interval periods, we reject the hypothesis that the value of life is constant over the workers' life cycle. In the case of the one-year interval estimator, the test statistic ranges from 443 to 540 for comparisons of the constant function with polynomials of order two through six. ${ }^{31}$ In the case of the five-year interval estimator, the test statistic ranges from 54.3 to 81.6 for the same comparisons. For the latter hypothesis, we specified the age polynomial function as linear, but such an approach yielded a negative coefficient estimate that clearly could not be distinguished 
from zero. The test of overidentifying restrictions rejected the linear specification in comparison to all higher order polynomials. It should also be noted that all order two through order six polynomials resulted in similar inverted U-shaped relationships between the value of a statistical life and age.

\section{Implications for the Value of a Statistical Life-Year}

The preceding section illustrates the estimated VSL-age profile consistent with the theory model presented in Section I and with previous simulations published in the literature. The implicit assumptions underlying the value of a statistical life-year (VSLY) approach, which require the value of life to be decreasing with age at all ages, are rejected by our data. In light of the common application of VSLYs in evaluations of medical interventions, Food and Drug Administration regulations, and in the sensitivity analyses of Environmental Protection Agency regulations, we have estimated age-specific VSLYs based on our age-specific VSLs.

To construct values of statistical life-years, we have annuitized age-specific VSLs based on age-specific years of life expectancy for 1996 (L) and an assumed discount rate of 3 percent (r) $:^{32}$

$$
V S L Y=\frac{r V S L}{1-(1+r)^{-L}}
$$

Table 5 presents these calculations for the one-year interval minimum distance estimator depicted in Figure 6 and for the age group subsample results presented in Table 3. Figure 7 depicts graphically the VSLYs derived from the one-year interval minimum distance estimator VSLs.

VSLYs follow a similar inverted U-shaped relationship over the life cycle as depicted for VSL. While the increase in VSLY is clearly expected for young workers (VSL is increasing and 
life expectancy is decreasing), the monotonic decrease in VSLY after its peak indicates that agespecific VSLs are decreasing at a faster rate than life expectancy. The peak VSLY occurs two years later in the life cycle than the peak VSL for the one-year interval minimum distance estimator. In both of the illustrations, the VSLY is decreasing with age after its peak. The variation across age is lower for VSLYs than for VSLs. For example, the peak VSL in the age group regressions ( $\$ 7.62$ million) is 2.6 times larger than the VSL for the oldest age group ( $\$ 2.93$ million), but the corresponding peak VSLY is only 1.9 times larger than the VSLY for the oldest age group. While VSLY decreases with age after its peak based on our analyses, it does so at a decreasing rate.

\section{Conclusion}

The implications of wage-risk tradeoffs for the dependency of VSL on age is consistent based on all three sets of empirical estimates: the age-risk interactions, estimation for separate age groups, and a minimum distance estimator derived from age-specific VSLs. For each case, the VSL rises and then falls with age, displaying an inverted U-shaped relationship. The minimum distance estimator results are perhaps most instructive, as they indicate a reasonably flat inverted-U. In terms of the appropriate "senior discount," workers in our sample in their early 60s have a VSL of $\$ 2.5-\$ 3.0$ million, which is about $30-40$ percent lower than the market average and between one-third and one-half the size of the VSLs for prime-aged workers.

The result that the VSL rises and falls with age is of both theoretical and policy interest. Theoretical analysis of VSL over the life cycle suggests such a relationship may exist, particularly in situations in which there are insurance and capital market imperfections. The results are supportive of these models rather than those that generate steadily declining VSL with 
age, such as some models with perfect annuity and insurance markets. VSL is not steadily declining with age even though the amount of expected lifetime at stake, which is the good being traded, steadily declines with age. As the life-cycle models indicate, this result is not surprising since the VSL-age linkage depends on factors such as the life-cycle consumption pattern, which also displays a similar temporal structure.

In terms of policy implications, this analysis does not provide support for approaches that focus only on the remaining quantity of life as the valued attribute. Both the value per life-year approach and the quality-adjusted life year methodology yield a steadily decreasing VSL with age, whereas the revealed preferences of workers' risk decisions indicate a quite different relationship that rises and then declines with age. Explicit construction of age-specific values of statistical life-years from our age-VSL profiles show that the value of a statistical life-year varies with age. Likewise, there is no support for the standard practice of transferring VSLs from studies based on the average of the labor market to risk contexts specific to the elderly population. There is an inverted U-shaped relationship with a fairly flat upper tail in our sample. Individuals make decisions over risk and income that clearly indicates that the value of their life varies with age, but the relationship is not a simple one. 


\section{References}

Anderson, R.N. (1998). United States Abridged Life Tables, 1996. National Vital Statistics Reports 47(13).

Arnould, R.J. and L.M. Nichols. (1983). "Wage-Risk Premiums and Workers' Compensation: A Refinement of Estimates of Compensating Wage Differential." Journal of Political Economy 91(2): 332-340.

Arthur, W.B. (1981). “The Economics of Risks to Life.” American Economic Review 71(1): 5464.

Baranzini, A. and G. Ferro Luzzi. (2001). “The Economic Value of Risks to Life: Evidence from the Swiss Labour Market.” Swiss Journal of Economics and Statistics 137(2): 149170.

Chamberlain, G. (1984). "Panel Data.” In: Z. Griliches and M.D. Intriligator, (eds.), Handbook of Econometrics, Volume II, pages 1247-1318.

Corso, P.S., J.K. Hammitt, and J.D. Graham. (2001). "Valuing Mortality-Risk Reduction: Using Visual Aids to Improve the Validity of Contingent Valuation." Journal of Risk and Uncertainty 23(2): 165-184. 
Cropper, M.L. and F.G. Sussman. (1988). "Families and the Economics of Risks to Life." American Economic Review 78(1): 255-260.

Dreyfus, M.K. and W.K. Viscusi. (1995). "Rates of Time Preference and Consumer Valuations of Automobile Safety and Fuel Efficiency.” Journal of Law and Economics 38: 79-105.

Hammitt, J.K. and J.-T. Liu. (2003). "Effects of Disease Type and Latency on the Value of Mortality Risk.” Harvard School of Public Health Working Paper, January 2003, Draft.

Hara Associates Inc. (2000). Benefit/Cost Analysis of Proposed Tobacco Products Information Regulations. Prepared for Health Canada and Consulting and Audit Canada. Ottawa, Ontario. June 5, 2000.

Hersch, J. (1998). “Compensating Differentials for Gender-Specific Job Injury Risks.” American Economic Review 88(3): 598-627.

Johannesson, M., P.-O. Johansson, and K.-G. Lofgren. (1997). “On the Value of Changes in Life Expectancy: Blips Versus Parametric Changes." Journal of Risk and Uncertainty 15: 221-239.

Johansson, P.-O. (2002). "On the Definition and Age-Dependency of the Value of a Statistical Life." Journal of Risk and Uncertainty 25(3): 251-263. 
(2001). "Is there a Meaningful Definition of the Value of a Statistical Life?" Journal of Health Economics 20: 131-139.

(1996). "On the Value of Changes in Life Expectancy." Journal of Health Economics 15: $105-113$.

Jones-Lee, M.W. 1989. The Economics of Safety and Physical Risk. Oxford: Basil Blackwell.

Jones-Lee, M.W., W.M. Hammerton, and P.R. Philips. (1985). "The Value of Safety: Results of a National Sample Survey.” Economic Journal 95: 49-72.

Krupnick, A., Alberini, A., Cropper, M., Simon, N., O’Brien, B., Goeree, R., and Heintzelman, M. (2002). “Age, Health, and the Willingness to Pay for Mortality Risk Reductions: A Contingent Valuation Survey of Ontario Residents." Journal of Risk and Uncertainty 24(2): 161-186.

Leeth, J.D. and J. Ruser. (2003). “Compensating Wage Differentials for Fatal and Nonfatal Injury Risk by Gender and Race.” Journal of Risk and Uncertainty 27(3): 257-277.

Meng, R. (1989). “Compensating Differences in the Canadian Labour Market.” Canadian Journal of Economics 22(2): 413-424. 
Meng, R.A. and D.A. Smith. (1990). "The Valuation of Risk of Death in Public Sector Decision-Making." Canadian Public Policy - Analyse de Politiques 16(2): 137-144.

Moore, M.J. and W.K. Viscusi. (1990). "Models for Estimating Discount Rates for Long-Term Health Risks Using Labor Market Data." Journal of Risk and Uncertainty 3: 381-401.

National Safety Council. (2002). Injury Facts, 2002 Edition. Itasca, IL: National Safety Council.

Persson, U., A. Norinder, K. Hjalte, and K. Gralen. (2001). "The Value of a Statistical Life in Transport: Findings from a New Contingent Valuation Study in Sweden.” Journal of Risk and Uncertainty 23(2): 121-134.

Rosen, S. (1988). "The Value of Changes in Life Expectancy." Journal of Risk and Uncertainty 1: $285-304$.

Shanmugam, K.R. (1996/7). "The Value of Life: Estimates from Indian Labour Market.” Indian Economic Journal 44(4): 105-114.

Shanmugam, K.R. (2001). "Self Selection Bias in the Estimates of Compensating Differentials for Job Risks in India.” Journal of Risk and Uncertainty 22(3): 263-275. 
Shepard, D.S. and R.J. Zeckhauser. (1984). "Survival Versus Consumption.” Management Science 30(4): 423-439.

Smith, V.K. and W.H. Desvousges. (1987). "An Empirical Analysis of the Economic Value of Risk Changes." Journal of Political Economy 95(1): 89-114.

Thaler, R. and S. Rosen. (1975). "The Value of Saving a life: Evidence from the Labor Market.” In: N.E. Terleckyj, (ed.), Household Production and Consumption. New York: Columbia University Press. Pp. 265-298.

Viscusi, W.K. (1979). Employment Hazards: An Investigation of Market Performance. Cambridge, MA: Harvard University Press.

Viscusi, W.K. (2004). The Value of Life: Estimates with Risks by Occupation and Industry. Economic Inquiry 42(1): 29-48.

Viscusi, W.K. and J.E. Aldy. (2003). "The Value of a Statistical Life: A Critical Review of Market Estimates Throughout the World.” Journal of Risk and Uncertainty 27(1): 5-76.

Viscusi, W. K. and J. Hersch, “Cigarette Smokers as Risk Takers.” Review of Economics and Statistics, 83 (2), 269-280. 
* Aldy: Department of Economics, Littauer Center, Harvard University, Cambridge, MA 02138 (e-mail: aldy@fas.harvard.edu); Viscusi: Harvard Law School, Hauser Hall 302, Cambridge, MA 02138 (e-mail: kip@law.harvard.edu). Aldy’s research is supported by the Environmental Protection Agency STAR Fellowship program and the Switzer Environmental Fellowship program. Viscusi's research is supported by the Harvard Olin Center for Law, Economics, and Business. The authors express gratitude to the Bureau of Labor Statistics for permission to use the CFOI fatality data. Neither the BLS nor any other government agency bears any responsibility for the risk measures calculated or the results in this paper. David Cutler, Bryan Graham, and Seamus Smyth provided very constructive comments on an earlier draft and we thank participants of the Harvard Environmental Economics and Policy Seminar for their comments.

${ }^{1}$ In the "senior discount" analyses, the EPA provided two alternatives to account for age. One approach was based on a standard value of a statistical life-year approach that explicitly accounts for life expectancy. The second approach assumed that individuals over age 70 had a value of statistical life equal to 63 percent of the value for those under 70 .

${ }^{2}$ Similarly, the European Union and Canada have endorsed age adjustments as well. See Johansson (2001) and Hara Associates (2000).

${ }^{3}$ For a sense of the political reaction and USEPA's decision to discontinue the use of an agebased value of statistical life, refer to "EPA Drops Age-Based Cost Studies," New York Times, May 8, 2003; “EPA to Stop 'Death Discount' to Value New Regulations," Wall Street Journal, May 8, 2003; and "Under Fire, EPA Drops the 'Senior Death Discount,"” Washington Post, May 13, 2003. 
${ }^{4}$ These studies are reviewed in Section 8 of Viscusi and Aldy (2003).

${ }^{5}$ Consider the following results from representative regression models from these studies. The VSL is negative for all workers over age 42 based on Thaler and Rosen (1975), at age 48 based on Viscusi (1979), at 49 for Arnould and Nichols (1983), at 56 for Meng (1989), and at 60 for Baranzini and Ferro Luzzi (2001). The other three studies, based on analyses of the Indian labor market (Shanmugam 1996/7, 2001) and the Canadian labor market (Meng and Smith 1990), found statistically insignificant coefficient estimates.

${ }^{6}$ Viscusi and Aldy (2003) provide a review of those studies, which include labor market and product market studies, such as Moore and Viscusi (1990) and Dreyfus and Viscusi (1995).

${ }^{7}$ Their finding that a 70-year old's willingness-to-pay (WTP) is about one-third less than the WTP of those aged 50 to 70 years was a key input in the Environmental Protection Agency's recent analysis of the Clear Skies initiative. Two important caveats merit attention. First, as the authors note, the intercept in the WTP bid regression model, which represents the age effect of the $\geq 70$-years old age group on WTP, is not statistically significant, although the age group indicator variable coefficients are all significant for age groups 40-49, 50-59, and 60-69. Thus, the estimate of the $\geq 70$-years old age group VSL is based on a rather imprecise estimate, as is the comparison between the $<70$-years and $\geq 70$-years populations. Second, the age group indicator variable coefficients imply an inverted-U for VSL over the life cycle. The authors indicate (in note 22) that with a more stringent data cleaning criterion, they estimate quadratic age regression specifications that yield an inverted-U with statistically significant coefficient estimates on the age and age $^{2}$ variables. Note that while other studies' sample screens include all adult-aged individuals, the Krupnick et al. study focuses on individuals 40 to 75 years of age. 
${ }^{8}$ All VSL estimates are presented in 1996 dollars in this paper. All VSL estimates should be increased 14.7 percent to convert them to 2002 dollars, based on the CPI-U deflator.

${ }^{9}$ See Viscusi (1979), Rosen (1988), and Viscusi and Aldy (2003), among many others, for details on such one-period models.

${ }^{10}$ To simplify notation, we have followed Shepard and Zeckhauser and assumed that the rate of time preference in the discount function is equal to the rate of return on assets, and that this rate is time-invariant. Allowing for the rate of time preference to differ from the return on assets would not substantively impact the primary conclusion of this analysis that the VSL-age relationship is ambiguous.

${ }^{11}$ Note that the survival function, $\sigma[t ; \tau, p(t)]$, and the discount function, $e^{-r t}$, implicitly enter equation (12) through their influence on the optimal consumption and job fatality risk paths.

${ }^{12}$ The availability of the CFOI data set has allowed analysts to construct job-related mortality rates in a variety of ways. Viscusi (forthcoming) used this occupational fatality data set to construct mortality rates by industry and by industry and occupation, while Leeth and Ruser (forthcoming) constructed job-related mortality rates by race, gender, and occupation.

${ }^{13}$ We have omitted the CFOI's $\leq 15$ and $\geq 65$ age groups in our empirical analyses.

${ }^{14}$ We have omitted the mining industry from Figures 1 and 2. Mining risk levels greatly exceed those for the industries shown, and inclusion of mining would obscure the trends in the other industries. For injury risks in the mining industry, the probability of an injury is always decreasing in age. For mortality risks, the probability of death in the mining industry peaks in the early 20s, but is increasing in age for individuals 35 to 64 years old.

${ }^{15}$ While most fatal accident rates for the elderly are higher than for younger groups, the relationship between age and accidents is often not monotonic. For example, motor vehicle 
accidents have a U-shaped pattern, with the lowest rate being for 45-64 year olds. Death rates from falls steadily rise with age. See the National Safety Council (2002), especially pages 8-12 for age-related accident statistics.

16 This analysis generalizes the hedonic model analysis for heterogeneous worker groups using the model developed for an evaluation of smokers and nonsmokers by Viscusi and Hersch (2001). Their worker groups differ in their safety-related productivity as well as in their attitudes toward risk.

${ }^{17}$ See Viscusi and Aldy (2003) for a review of these studies.

18 The procedures for calculating the workers' compensation benefit variable are discussed in more detail in Viscusi (forthcoming), which also provides supporting references.

19 For the specifications that include Mortality Risk and Mortality Risk interacted with Age, the age-specific VSL would be characterized by: $V S L_{\tau}=\left(\hat{\gamma}_{1}+\hat{\gamma}_{2} * A g e\right) * \bar{w}_{\tau} * 2,000 * 100,000$, where we account for the age-specific mean wage in the calculation.

${ }^{20}$ Viscusi (forthcoming) estimated a VSL of $\$ 4.7$ million (1997 dollars) for his entire sample based on occupation-industry mortality risk (CFOI) data. The test statistic for the comparison of the two VSLs is a variant of the Wald statistic: $W=\left(V \hat{S} L_{i}-V \hat{S} L_{j}\right)^{2}\left[\operatorname{Var}\left(V \hat{S} L_{i}\right)+\operatorname{Var}\left(V \hat{S} L_{j}\right)\right]^{-1} \sim \chi_{1}^{2}$. This test yields $\mathrm{W}=0.381$, which is not statistically significant at any conventional level. ${ }^{21}$ Refer to Hersch (1998), Viscusi and Hersch (2001), and Viscusi (forthcoming) as examples of papers in this literature that account for this type of correlation.

${ }^{22}$ We used the state's average worker's compensation benefit and an indicator variable for whether the state has a Republican governor as instruments. These appear to be valid instruments: they are both statistically significant determinants of the replacement rate (at the 1 
percent level) while controlling for all other explanatory variables in the hedonic wage regression, neither variable offers any statistically meaningful explanation of the $\log$ (wage) (statistical significance at the 30 and 45 percent levels), and a test of overidentifying restrictions indicate that the instruments are not correlated with the error term (test statistic $=0.234$ ). While we have presented these two-stage least squares results, Hausman tests do not support the conclusion of endogeneity. The test statistic for the worker's compensation replacement rate is 1.42.

${ }^{23}$ For the age-risk interaction specification, we have estimated age-specific VSLs using agespecific mean wages.

${ }^{24}$ We have also conducted the same two stage least squares specifications as in column (2) of Table 2. These have very modest impacts on the results: there is virtually no difference in qualitative conclusions about statistical significance, and the estimated VSL point estimates differ from the OLS results by less than $\$ 0.5$ million in all five regressions.

${ }^{25} \mathrm{We}$ also conducted the same tests based on the regression equation coefficient estimates on the mortality risk variable and their variances. These tests yield the same results for these age group comparisons except for the tests for the 18-24 year old and the next two age groups. With the coefficient-based tests, the Wald statistics for these two comparisons are not significant. The differences between the coefficient-based and VSL-based Wald tests appear to be driven by the significant growth in labor income through the early to middle stages of the worker's life cycle.

26 We also evaluated whether the higher VSLs for individuals in the 25-44 age range reflect major life-cycle events such as marriage or having children, and not variations in age. We replicated the regression model presented in Table 2, Column 3 by including a Mortality Risk*Married term in one specification and a Mortality Risk*Children term in another 
specification (in which we also included Children, defined as under 18 children residing with the worker, as an independent explanatory variable). If either of these interactions are positive, and if it influences the magnitude and/or statistical significance of the Mortality Risk*Age interaction, then the effects of age on the VSL revealed in the preceding analyses may have actually reflected the effects of the family, and not one's age, on the estimated VSL. In the former case, the interaction of mortality risk and the married indicator variable was not statistically significant, and the coefficient estimates on Mortality Risk and Mortality Risk*Age were virtually unchanged from the specification reported in Table 2, Column 3. In the latter case, we tested the effect of children by characterizing this variable as an indicator variable for whether the worker has any children and as a discrete variable for the number of children the worker has. In both cases, the interaction of Mortality Risk and Children was statistically significant and negative, but it did not have a meaningful impact on the VSL, and the coefficient estimates for the Mortality Risk and Mortality Risk*Age interaction variables were still statistically significant at the one percent level and their magnitudes essentially unchanged. We also included Mortality Risk*Married and Mortality Risk*Children interactions in the age group regressions, but these were virtually all statistically insignificant. The variations in VSL by age do not appear to be driven by changes in family status.

${ }^{27}$ By construction, our approach generates a diagonal variance-covariance matrix. Using independent regressions to estimate the VSLs in the first stage results in zero covariances among the VSL estimates.

${ }^{28}$ All regressions are estimated with White heteroskedasticity-corrected standard errors. 
${ }^{29}$ While not a focus of this paper, the coefficient estimates associated with the injury risk variable and the workers' compensation replacement rate variable are statistically significant at the 1 percent level in all of the one-year and five-year interval regressions.

${ }^{30}$ We have employed a test of overidentifying restrictions to assess the appropriate order of the polynomial in age. If we assume that $\theta$ is a $\mathrm{Kx} 1$ vector, then a restricted parameter vector, $\alpha$, which is $\mathrm{Rx} 1$ where $\mathrm{R}<\mathrm{K}$, can be estimated by some function, $b(\alpha)$. The following test statistic can then be used to evaluate the restrictions on the parameter vector:

$$
N[V \hat{S} L-b(\hat{\alpha})]^{\prime} \hat{V}^{-1}[V \hat{S} L-b(\hat{\alpha})]-N[V \hat{S} L-a(\hat{\theta})]^{\prime} \hat{V}^{-1}[V \hat{S} L-a(\hat{\theta})] \sim \chi_{K-R}^{2}
$$

For the five-year interval minimum distance estimator, one could not reject the third-order polynomial in favor of any higher order polynomial based on this test. For the one-year interval minimum distance estimator, the fifth-order polynomial was preferred (it could not be rejected for the sixth-order polynomial, while one would reject the third-order and fourth-order polynomials in favor of the fifth-order polynomial). We have presented the third-order polynomials for both approaches to facilitate comparison. The fifth-order polynomial for the 1year interval estimator still takes an inverted-U shape, with a peak of $\$ 7.6$ million at age 34 and it declines monotonically from there until age 62 when the VSL is about $\$ 880,000$.

${ }^{31}$ Note that $\chi^{2} \leq 16.81$ at the 1 percent level for the various tests comparing the constant function with the higher order functions.

${ }^{32}$ We have also calculated VSLYs based on a 7 percent discount rate (the current preferred rate by the Office of Management and Budget for evaluating government regulations). The higher discount rate yields larger VSLYs and a more pronounced inverted U-shaped VSLY-age relationship. 
Table 1. Descriptive Statistics for the Sample

\begin{tabular}{|c|c|c|}
\hline Variable & Description & $\begin{array}{c}\text { Mean } \\
\text { (Standard Deviation) } \\
\end{array}$ \\
\hline Log(Wage) & $\begin{array}{l}\text { Natural logarithm of after-tax hourly wage or hourly } \\
\text { equivalent of salary. }\end{array}$ & $\begin{array}{l}\$ 2.26 \\
(0.51)\end{array}$ \\
\hline Age & Age of worker in years. & $\begin{array}{l}38.7 \\
(10.7)\end{array}$ \\
\hline Black & Indicator variable for whether worker is black. & $\begin{array}{l}0.10 \\
(0.30)\end{array}$ \\
\hline Native American & $\begin{array}{l}\text { Indicator variable for whether worker is Native } \\
\text { American. }\end{array}$ & $\begin{array}{l}0.010 \\
(0.10)\end{array}$ \\
\hline Asian & Indicator variable for whether worker is Asian. & $\begin{array}{l}0.037 \\
(0.19)\end{array}$ \\
\hline Hispanic & Indicator variable for whether worker is Hispanic. & $\begin{array}{l}0.079 \\
(0.27)\end{array}$ \\
\hline Female & Indicator variable for whether worker is female. & $\begin{array}{l}0.44 \\
(0.50)\end{array}$ \\
\hline Education & $\begin{array}{l}\text { Education level of worker. Education }=12 \\
\text { represents a high school graduate. }\end{array}$ & $\begin{array}{l}14.1 \\
(2.34)\end{array}$ \\
\hline Married & Indicator variable for whether worker is married. & $\begin{array}{l}0.61 \\
(0.49)\end{array}$ \\
\hline Union Member & $\begin{array}{l}\text { Indicator variable for whether worker is a union } \\
\text { member. }\end{array}$ & $\begin{array}{l}0.17 \\
(0.37)\end{array}$ \\
\hline Public Sector Job & $\begin{array}{l}\text { Indicator variable for whether worker is employed in } \\
\text { a public sector job. }\end{array}$ & $\begin{array}{l}0.064 \\
(0.24)\end{array}$ \\
\hline Urban Resident & $\begin{array}{l}\text { Indicator variable for whether worker resides in an } \\
\text { urban area. }\end{array}$ & $\begin{array}{l}0.79 \\
(0.41)\end{array}$ \\
\hline Mortality Risk & $\begin{array}{l}\text { Annual occupational mortality risk, per } 100,000 \text { full- } \\
\text { time workers }\end{array}$ & $\begin{array}{l}4.1 \\
(5.3)\end{array}$ \\
\hline Injury Risk & Annual injury risk for full-time workers. & $\begin{array}{l}0.015 \\
(0.013)\end{array}$ \\
\hline $\begin{array}{l}\text { Workers } \\
\text { Compensation } \\
\text { Replacement Rate }\end{array}$ & $\begin{array}{l}\text { Injury Risk*Expected Workers' Compensation } \\
\text { Benefit for the worker in his or her state of residence. }\end{array}$ & $\begin{array}{l}0.012 \\
(0.011)\end{array}$ \\
\hline
\end{tabular}

$\mathrm{N}=116,632$ 
Table 2. Linear and Risk-Age Interaction Hedonic Wage Regression Results

\begin{tabular}{|c|c|c|c|c|}
\hline Variable & $\begin{array}{c}\text { OLS } \\
(1) \\
\end{array}$ & $\begin{array}{c}\text { 2SLS } \\
(2) \\
\end{array}$ & $\begin{array}{c}\text { OLS } \\
(3) \\
\end{array}$ & $\begin{array}{c}\text { 2SLS } \\
(4) \\
\end{array}$ \\
\hline Age & $\begin{array}{c}0.0435 \\
(0.00070)^{*} \\
{[0.00085]^{*}}\end{array}$ & $\begin{array}{c}0.0425 \\
(0.0011)^{*} \\
{[0.0024]^{*}}\end{array}$ & $\begin{array}{c}0.0434 \\
(0.00070)^{*} \\
{[0.00085]^{*}}\end{array}$ & $\begin{array}{c}0.0424 \\
(0.0011)^{*} \\
{[0.0024]^{*}}\end{array}$ \\
\hline $\mathrm{Age}^{2}$ & $\begin{array}{l}-0.000454 \\
\left(8.7 \times 10^{-6}\right)^{*} \\
{\left[1.1 \times 10^{-5}\right]^{*}}\end{array}$ & $\begin{array}{c}-0.000443 \\
\left(1.2 \times 10^{-5}\right)^{*} \\
{\left[2.4 \times 10^{-5}\right]^{*}}\end{array}$ & $\begin{array}{l}-0.000448 \\
\left(8.8 \times 10^{-6}\right)^{*} \\
{\left[1.1 \times 10^{-5}\right]^{*}}\end{array}$ & $\begin{array}{c}-0.000437 \\
(0.000013)^{*} \\
{\left[2.6 \times 10^{-5}\right]^{*}}\end{array}$ \\
\hline Black & $\begin{array}{c}-0.112 \\
(0.0036)^{*} \\
{[0.0041]^{*}}\end{array}$ & $\begin{array}{c}-0.111 \\
(0.0037)^{*} \\
{[0.0044]^{*}}\end{array}$ & $\begin{array}{c}-0.112 \\
(0.0036)^{*} \\
{[0.0041]^{*}}\end{array}$ & $\begin{array}{c}-0.111 \\
(0.0037)^{*} \\
{[0.0044]^{*}}\end{array}$ \\
\hline Native American & $\begin{array}{l}-0.0199 \\
(0.011) \\
{[0.016]}\end{array}$ & $\begin{array}{c}-0.0206 \\
(0.011)^{* * *} \\
{[0.016]}\end{array}$ & $\begin{array}{l}-0.0198 \\
(0.011) \\
{[0.016]}\end{array}$ & $\begin{array}{c}-0.0205 \\
(0.011)^{* * *} \\
{[0.016]}\end{array}$ \\
\hline Asian & $\begin{array}{c}-0.0733 \\
(0.0058)^{*} \\
{[0.0079]^{*}}\end{array}$ & $\begin{array}{c}-0.0711 \\
(0.0060)^{*} \\
{[0.0093]^{*}}\end{array}$ & $\begin{array}{c}-0.0732 \\
(0.0058)^{*} \\
{[0.0079]^{*}}\end{array}$ & $\begin{array}{c}-0.0709 \\
(0.0061)^{*} \\
{[0.0094]^{*}}\end{array}$ \\
\hline Hispanic & $\begin{array}{c}-0.0830 \\
(0.0042)^{*} \\
{[0.0065]^{*}}\end{array}$ & $\begin{array}{c}-0.0826 \\
(0.0042)^{*} \\
{[0.0066]^{*}}\end{array}$ & $\begin{array}{c}-0.0832 \\
(0.0042)^{*} \\
{[0.0065]^{*}}\end{array}$ & $\begin{array}{c}-0.0828 \\
(0.0042)^{*} \\
{[0.0066]^{*}}\end{array}$ \\
\hline Female & $\begin{array}{c}-0.186 \\
(0.0024)^{*} \\
{[0.0040]^{*}}\end{array}$ & $\begin{array}{c}-0.180 \\
(0.0057)^{*} \\
{[0.014]^{*}}\end{array}$ & $\begin{array}{c}-0.186 \\
(0.0024)^{*} \\
{[0.0040]^{*}}\end{array}$ & $\begin{array}{c}-0.180 \\
(0.0057)^{*} \\
{[0.0014]^{*}}\end{array}$ \\
\hline Education & $\begin{array}{c}0.0502 \\
(0.00060)^{*} \\
{[0.00091]^{*}}\end{array}$ & $\begin{array}{c}0.0488 \\
(0.0013)^{*} \\
{[0.0031]^{*}}\end{array}$ & $\begin{array}{c}0.0501 \\
(0.00060)^{*} \\
{[0.00091]^{*}}\end{array}$ & $\begin{array}{c}0.0487 \\
(0.0013)^{*} \\
{[0.0032]^{*}}\end{array}$ \\
\hline Married & $\begin{array}{c}0.0694 \\
(0.0023)^{*} \\
{[0.0026]^{*}}\end{array}$ & $\begin{array}{c}0.0617 \\
(0.0069)^{*} \\
{[0.017]^{*}}\end{array}$ & $\begin{array}{c}0.0695 \\
(0.0023)^{*} \\
{[0.0026]^{*}}\end{array}$ & $\begin{array}{c}0.0618 \\
(0.0069)^{*} \\
{[0.017]^{*}}\end{array}$ \\
\hline Union Member & $\begin{array}{c}0.126 \\
(0.0028)^{*} \\
{[0.0057]^{*}}\end{array}$ & $\begin{array}{c}0.125 \\
(0.0030)^{*} \\
{[0.0062]^{*}}\end{array}$ & $\begin{array}{c}0.126 \\
(0.0028)^{*} \\
{[0.0057]^{*}}\end{array}$ & $\begin{array}{c}0.125 \\
(0.0030)^{*} \\
{[0.0062]^{*}}\end{array}$ \\
\hline Public Sector Job & $\begin{array}{c}0.106 \\
(0.0048)^{*} \\
{[0.011]^{*}}\end{array}$ & $\begin{array}{c}0.110 \\
(0.0058)^{*} \\
{[0.015]^{*}}\end{array}$ & $\begin{array}{c}0.104 \\
(0.0048)^{*} \\
{[0.011]^{*}}\end{array}$ & $\begin{array}{c}0.108 \\
(0.0057)^{*} \\
{[0.014]^{*}}\end{array}$ \\
\hline Urban Resident & $\begin{array}{c}0.0965 \\
(0.0026)^{*} \\
{[0.0043]^{*}}\end{array}$ & $\begin{array}{c}0.0928 \\
(0.0041)^{*} \\
{[0.0092]^{*}}\end{array}$ & $\begin{array}{c}0.0965 \\
(0.0026)^{*} \\
{[0.0043]^{*}}\end{array}$ & $\begin{array}{c}0.0927 \\
(0.0041)^{*} \\
{[0.0092]^{*}}\end{array}$ \\
\hline Mortality Risk & $\begin{array}{c}0.00189 \\
(0.00024)^{*} \\
{[0.00052]^{*}}\end{array}$ & $\begin{array}{c}0.00178 \\
(0.00026)^{*} \\
{[0.00058]^{*}}\end{array}$ & $\begin{array}{c}0.00563 \\
(0.00091)^{*} \\
{[0.0012]^{*}}\end{array}$ & $\begin{array}{c}0.00618 \\
(0.0011)^{*} \\
{[0.0018]^{*}}\end{array}$ \\
\hline
\end{tabular}




\begin{tabular}{|c|c|c|c|c|}
\hline Variable & $\begin{array}{l}\text { OLS } \\
\text { (1) }\end{array}$ & $\begin{array}{l}2 \text { 2SLS } \\
(2)\end{array}$ & $\begin{array}{c}\text { OLS } \\
\text { (3) }\end{array}$ & $\begin{array}{c}\text { 2SLS } \\
\text { (4) }\end{array}$ \\
\hline Mortality Risk*Age & - & - & $\begin{array}{l}-9.23 \times 10^{-5} \\
\left(2.0 \times 10^{-5}\right)^{*} \\
{\left[2.4 \times 10^{-5}\right]^{*}}\end{array}$ & $\begin{array}{c}-0.000109 \\
\left(2.5 \times 10^{-5}\right)^{*} \\
{\left[4.5 \times 10^{-5}\right]^{* *}}\end{array}$ \\
\hline Injury Risk & $\begin{array}{l}44.073 \\
(0.37)^{*} \\
{[1.04]^{*}}\end{array}$ & $\begin{array}{l}52.297 \\
(6.92)^{*} \\
{[18.20]^{*}}\end{array}$ & $\begin{array}{l}44.106 \\
(0.37) * \\
{[1.03] *}\end{array}$ & $\begin{array}{l}52.317 \\
(6.92)^{*} \\
{[18.23]^{*}}\end{array}$ \\
\hline $\begin{array}{l}\text { Workers Compensation } \\
\text { Replacement Rate }\end{array}$ & $\begin{array}{l}-53.826 \\
(0.46)^{*} \\
{[1.27]^{*}}\end{array}$ & $\begin{array}{l}-63.997 \\
(8.55)^{*} \\
{[22.52]^{*}}\end{array}$ & $\begin{array}{l}-53.889 \\
(0.46)^{*} \\
{[1.27]^{*}}\end{array}$ & $\begin{array}{l}-64.049 \\
(8.56)^{*} \\
{[22.57]^{*}}\end{array}$ \\
\hline Constant & $\begin{array}{c}0.446 \\
(0.016)^{*} \\
{[0.024]^{*}}\end{array}$ & $\begin{array}{c}0.500 \\
(0.048)^{*} \\
{[0.12]^{*}}\end{array}$ & $\begin{array}{c}0.440 \\
(0.016)^{*} \\
{[0.024]^{*}}\end{array}$ & $\begin{array}{c}0.493 \\
(0.047)^{*} \\
{[0.12]^{*}}\end{array}$ \\
\hline $\mathrm{R}^{2}$ & 0.532 & 0.528 & 0.532 & 0.528 \\
\hline $\mathrm{N}$ & 116,632 & 116,632 & 116,632 & 116,632 \\
\hline $\begin{array}{l}\text { Mean In-Sample VSL } \\
\text { (95 percent confidence } \\
\text { interval) (millions } 96 \$ \text { ) }\end{array}$ & $\begin{array}{c}\$ 4.23 \\
(\$ 3.20-\$ 5.27)\end{array}$ & $\begin{array}{c}\$ 3.99 \\
(\$ 2.85-\$ 5.13)\end{array}$ & $\$ 4.28$ & $\$ 4.05$ \\
\hline
\end{tabular}

Dependent Variable: natural logarithm of hourly labor income.

All specifications include 9 1-digit occupation indicator variables and 8 regional indicator variables.

Robust (White) standard errors are presented in parentheses and standard errors accounting for within-group correlation are presented in brackets. The 95 percent confidence intervals are based on the robust standard errors.

Figure 4 presents the 95 percent confidence intervals for the specification in column (3).

* Indicates statistical significance at 1 percent level, two-tailed test.

** Indicates statistical significance at 5 percent level, two-tailed test.

*** Indicates statistical significance at 10 percent level, two-tailed test. 


\section{Table 3. Age Group Subsample Hedonic Wage Regressions}

\begin{tabular}{|c|c|c|c|c|c|}
\hline & $\begin{array}{c}18-24 \\
\text { Age Group }\end{array}$ & $\begin{array}{c}25-34 \\
\text { Age Group }\end{array}$ & $\begin{array}{c}35-44 \\
\text { Age Group }\end{array}$ & $\begin{array}{c}45-54 \\
\text { Age Group }\end{array}$ & $\begin{array}{c}55-62 \\
\text { Age Group }\end{array}$ \\
\hline Mortality Risk & $\begin{array}{c}0.00255 \\
(0.00079)^{*} \\
{[0.00090]^{*}}\end{array}$ & $\begin{array}{c}0.00350 \\
(0.00046)^{*} \\
{[0.00068]^{*}}\end{array}$ & $\begin{array}{c}0.00314 \\
(0.00048)^{*} \\
{[0.00088]^{*}}\end{array}$ & $\begin{array}{c}0.00153 \\
(0.00046)^{*} \\
{[0.00072]^{* *}}\end{array}$ & $\begin{array}{c}0.00120 \\
(0.00061)^{* *} \\
{[0.00070]^{* * *}}\end{array}$ \\
\hline $\mathrm{R}^{2}$ & 0.286 & 0.448 & 0.515 & 0.534 & 0.550 \\
\hline $\mathrm{N}$ & 11,641 & 32,774 & 35,611 & 26,731 & 9,875 \\
\hline $\begin{array}{l}\text { Mean In- } \\
\text { Sample VSL } \\
\text { (95 percent } \\
\text { confidence } \\
\text { interval) } \\
\text { (millions 96\$) }\end{array}$ & $\begin{array}{c}\$ 3.42 \\
(\$ 1.34-\$ 5.49)\end{array}$ & $\begin{array}{c}\$ 7.06 \\
(\$ 5.26-\$ 8.87)\end{array}$ & $\begin{array}{c}\$ 7.62 \\
(\$ 5.32-\$ 9.92)\end{array}$ & $\begin{array}{c}\$ 3.92 \\
(\$ 1.60-\$ 6.24)\end{array}$ & $\begin{array}{c}\$ 2.93 \\
(\$ 0.016-\$ 5.85)\end{array}$ \\
\hline
\end{tabular}

All specifications include the same set of control variables as those presented in columns (1) - (4) in Table 2.

Robust (White) standard errors are presented in parentheses and clustered standard errors are presented in brackets.

The 95 percent confidence intervals are based on the robust standard errors.

* Indicates statistical significance at 1 percent level, two-tailed test.

** Indicates statistical significance at 5 percent level, two-tailed test.

** Indicates statistical significance at 10 percent level, two-tailed test. 
Table 4. Minimum Distance Estimator Based on 5-Year Interval VSLs

\begin{tabular}{|c|c|}
\hline \multicolumn{2}{|c|}{$1^{\text {st }}$ Stage } \\
\hline Age Group & $\begin{array}{c}\text { VSL } \\
\text { (millions 1996\$) }\end{array}$ \\
\hline $18-22$ & $\$ 3.13^{*}$ \\
\hline $23-27$ & $\$ 4.14^{*}$ \\
\hline $28-32$ & $\$ 5.76^{*}$ \\
\hline $33-37$ & $\$ 5.68 *$ \\
\hline $38-42$ & $\$ 4.83 *$ \\
\hline $43-47$ & $\$ 3.63 *$ \\
\hline $48-52$ & $\$ 3.12 * *$ \\
\hline $53-57$ & $\$ 2.85 * *$ \\
\hline $58-62$ & $\$ 2.51 * * *$ \\
\hline \multicolumn{2}{|c|}{$2^{\text {nd }}$ Stage } \\
\hline Variable & Coefficient Estimate \\
\hline age & $\begin{array}{r}1.88 \times 10^{6} \\
\left(1.41 \times 10^{6}\right)\end{array}$ \\
\hline age $^{2}$ & $\begin{array}{l}-4.54 \times 10^{4} \\
\left(3.59 \times 10^{4}\right)\end{array}$ \\
\hline $\operatorname{age}^{3}$ & $\begin{array}{c}335.24 \\
(293.26)\end{array}$ \\
\hline constant & $\begin{array}{l}-1.92 \times 10^{7} \\
\left(1.76 \times 10^{7}\right)\end{array}$ \\
\hline $\mathrm{N}$ & 9 \\
\hline
\end{tabular}

Asymptotic standard errors are presented in parentheses.

* Indicates mortality risk variable coefficient used to construct VSL statistically significant at 1 percent level, twotailed test.

** Indicates mortality risk variable coefficient used to construct VSL statistically significant at 5 percent level, twotailed test.

*** Indicates mortality risk variable coefficient used to construct VSL statistically significant at 10 percent level, two-tailed test. 
Table 5. Age-Specific Value of Statistical Life-Years Based on Fitted VSLs from Minimum Distance Estimator and Age Group Subsample Regressions

\begin{tabular}{|c|c|c|}
\hline Age & $\begin{array}{c}\text { VSLY, based on } \\
\text { One-Year Interval MD } \\
\text { Estimator }\end{array}$ & $\begin{array}{l}\text { VSLY, based on Age Group } \\
\text { Regressions (Table 3) }\end{array}$ \\
\hline 18 & $\$ 40,330$ & \\
\hline 19 & $\$ 68,742$ & \\
\hline 20 & $\$ 94,897$ & \\
\hline 21 & $\$ 119,246$ & $\$ 126,653$ \\
\hline 22 & $\$ 141,993$ & \\
\hline 23 & $\$ 162,929$ & \\
\hline 24 & $\$ 181,806$ & \\
\hline 25 & $\$ 199,615$ & \\
\hline 26 & $\$ 215,276$ & \\
\hline 27 & $\$ 229,281$ & \\
\hline 28 & $\$ 242,206$ & \\
\hline 29 & $\$ 253,225$ & \\
\hline 30 & $\$ 263,149$ & $\$ 277,604$ \\
\hline 31 & $\$ 271,467$ & \\
\hline 32 & $\$ 278,669$ & \\
\hline 33 & $\$ 284,167$ & \\
\hline 34 & $\$ 288,609$ & \\
\hline 35 & $\$ 292,304$ & $\$ 332,735$ \\
\hline 36 & $\$ 294,566$ & \\
\hline 37 & $\$ 295,686$ & \\
\hline 38 & $\$ 295,626$ & \\
\hline 39 & $\$ 295,182$ & \\
\hline 40 & $\$ 293,547$ & \\
\hline 41 & $\$ 290,627$ & \\
\hline 42 & $\$ 287,278$ & \\
\hline
\end{tabular}




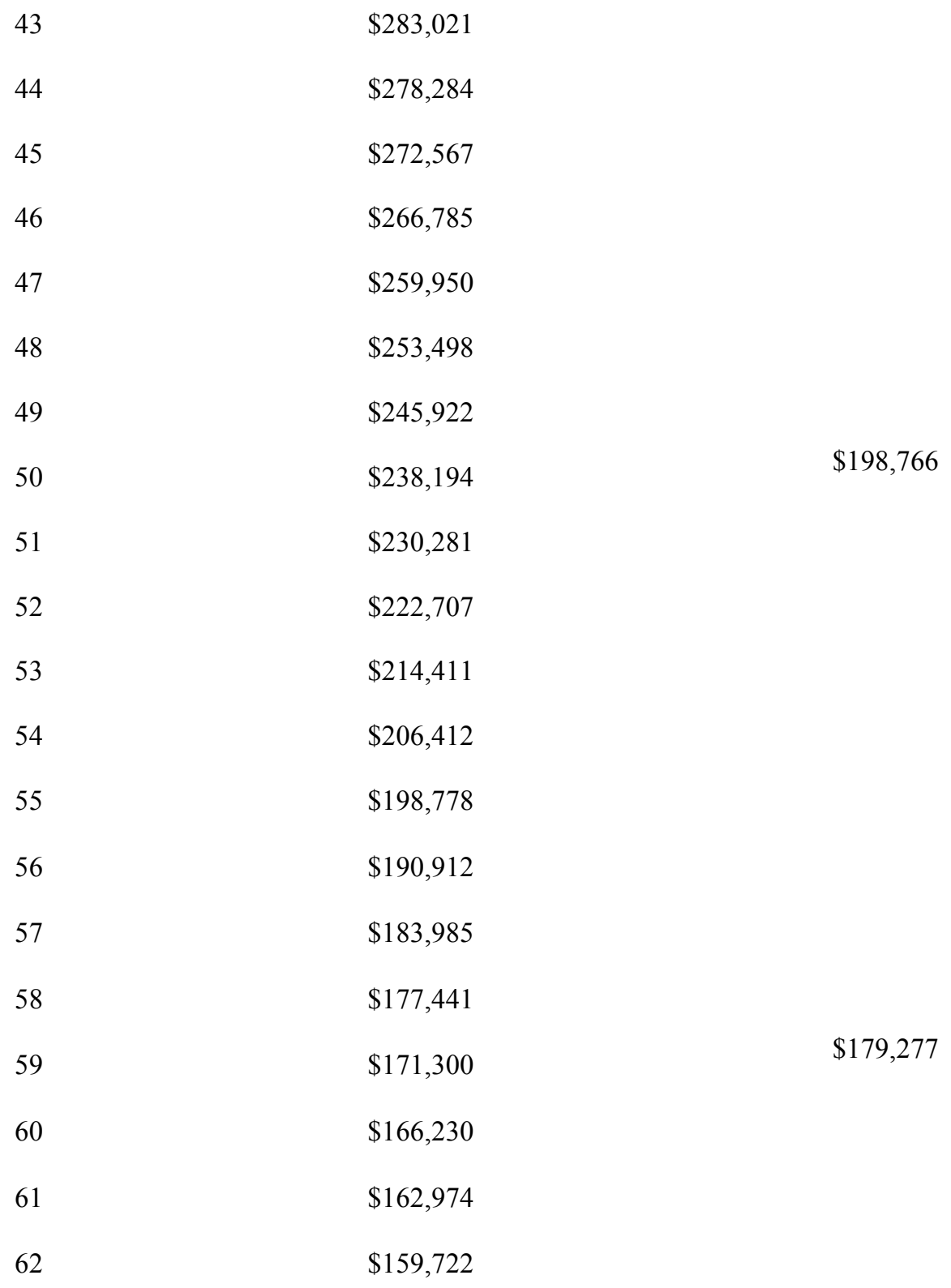

Note: All VSLYs estimated assuming a 3 percent discount rate and age-specific average remaining life expectancy estimated for 1996 (refer to Table 3 in Anderson 1998 for details). 
Figure 1. Lost Workday Injury Risk by Age and 1-Digit Industry, Annual Worker Injury Risk 1992-1995 Averages

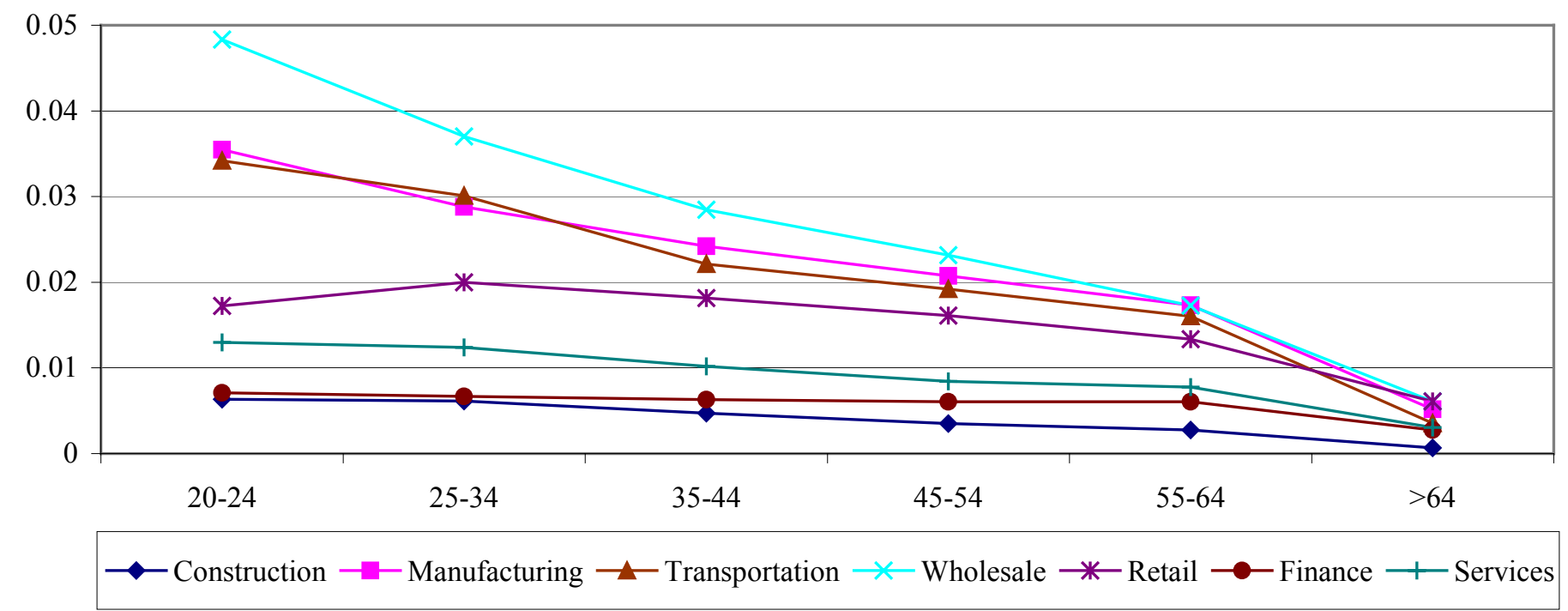

Notes: Constructed by authors with injury risk data for lost workday injuries from the BLS Injuries, Illnesses, and Fatalities Program, 1992-1995, and CPS MORG data files, 1992-1995. 
Annual Worker

Mortality Risk

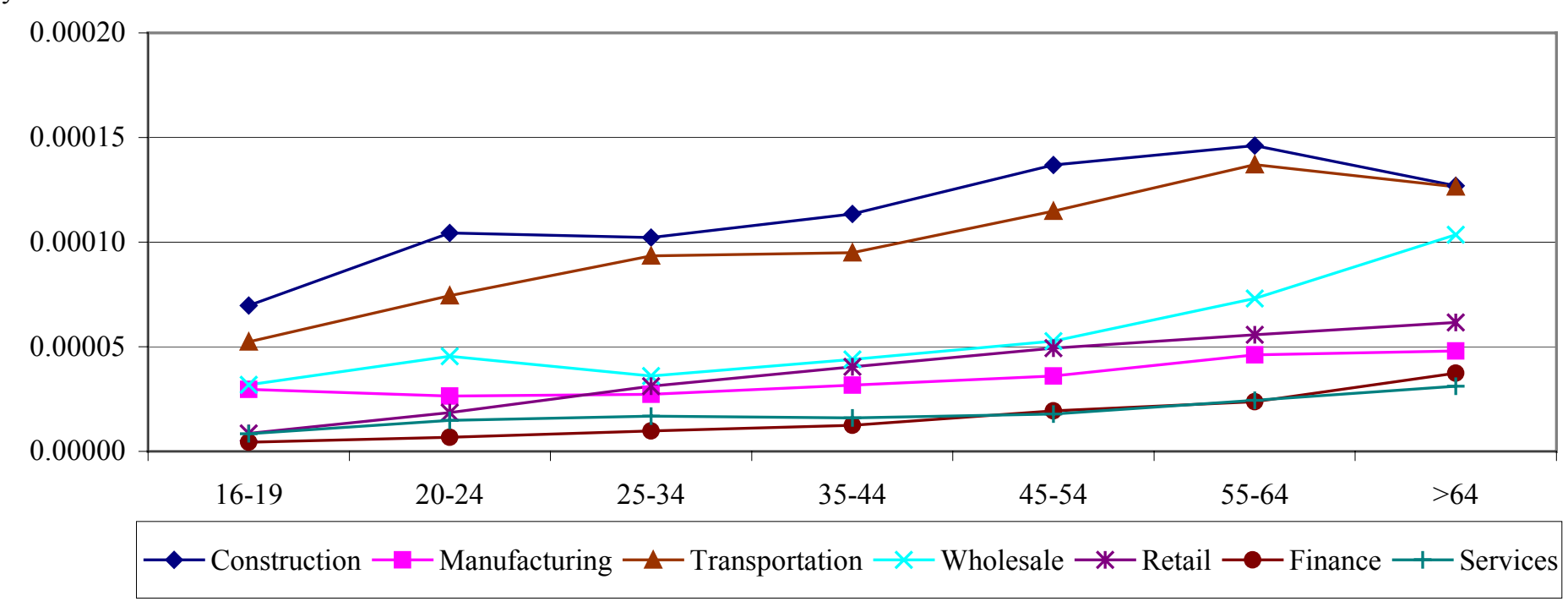

Notes: Constructed by authors with mortality risk data from the BLS Census of Fatal Occupational Injuries, 1992-1995, and CPS MORG data files, 1992-1995. 1992-1995 Averages

Figure 2. Mortality Risk by Age and 1-Digit Industry, 
Annual Worker Mortality Risk

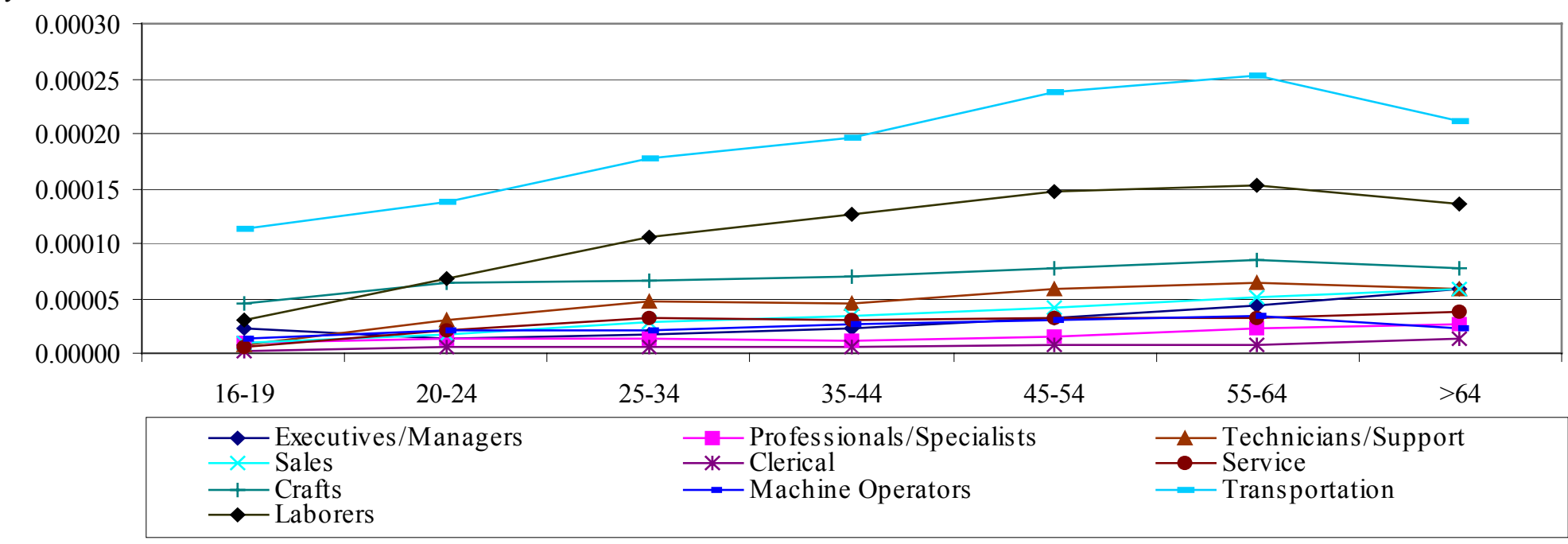

Notes: Constructed by authors with mortality risk data from the BLS Census of Fatal Occupational Injuries, 1992-1995, and CPS MORG data files, 1992-1995. 1992-1995 Averages

Figure 3. Mortality Risk by Age and 1-Digit Occupation, 
Figure 4. Value of a Statistical Life Based on Risk-Age Interaction

VSL Specification, with 95 Percent Confidence Interval

(millions 1996\$)

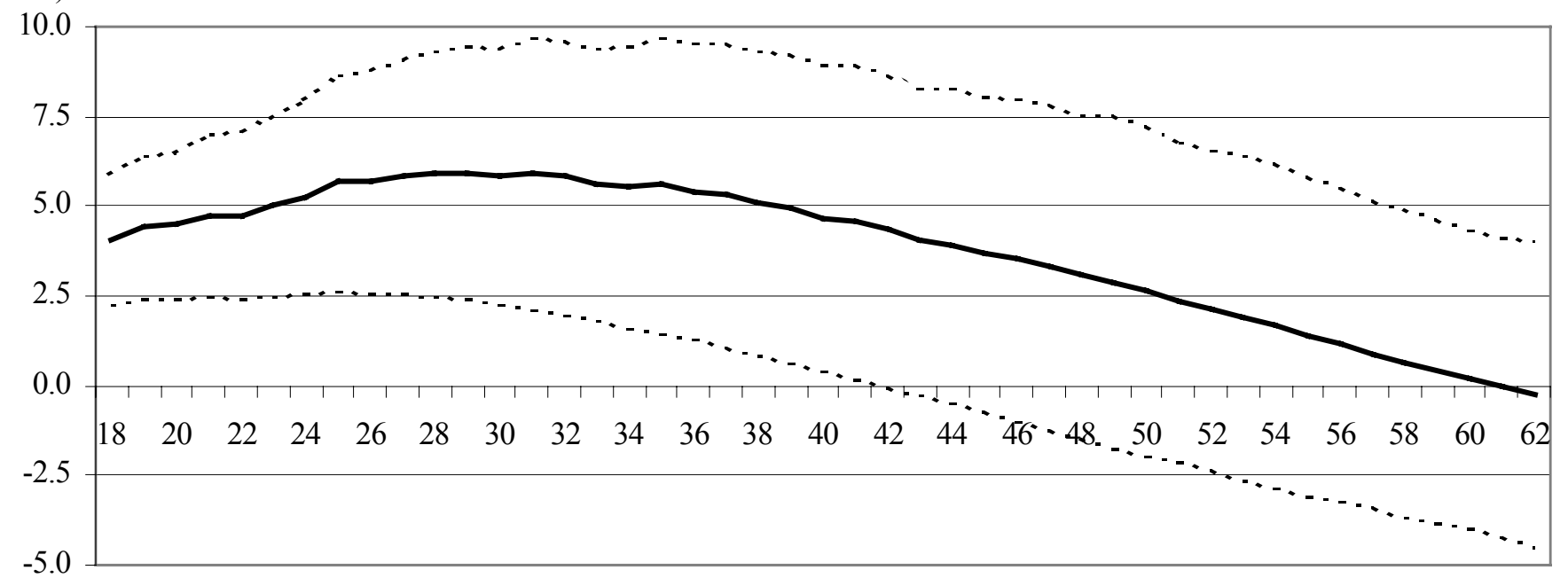

Notes. Based on regression specification (3) in Table 2. VSLs constructed with age-specific mean after-tax wages. 95 percent confidence interval based on robust standard errors. 
Figure 5. Value of a Statistical Life, Minimum Distance Estimator Based on 5Year Interval VSLs, with 95 Percent Confidence Interval

VSL

(millions 1996\$)

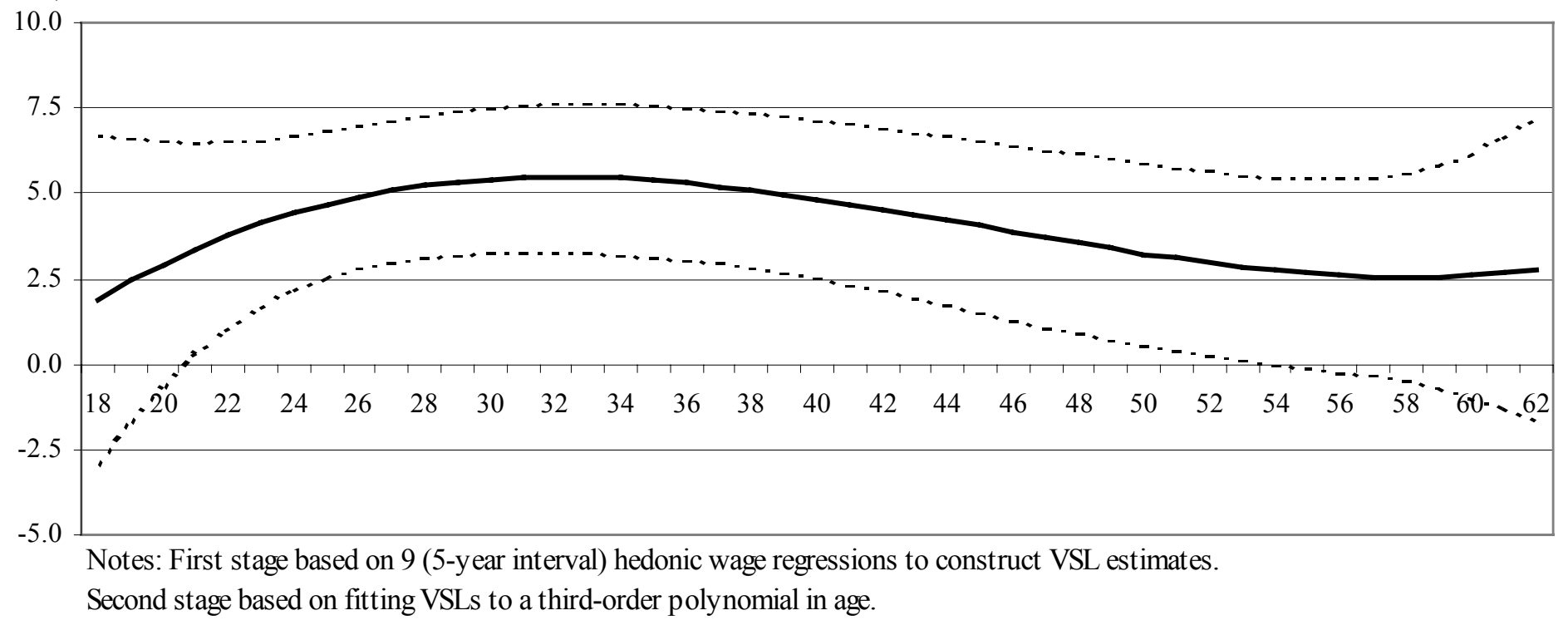


Figure 6. Value of a Statistical Life, Minimum Distance Estimator Based on 1VSL Year Interval VSLs, with 95 Percent Confidence Interval

(millions 1996\$)

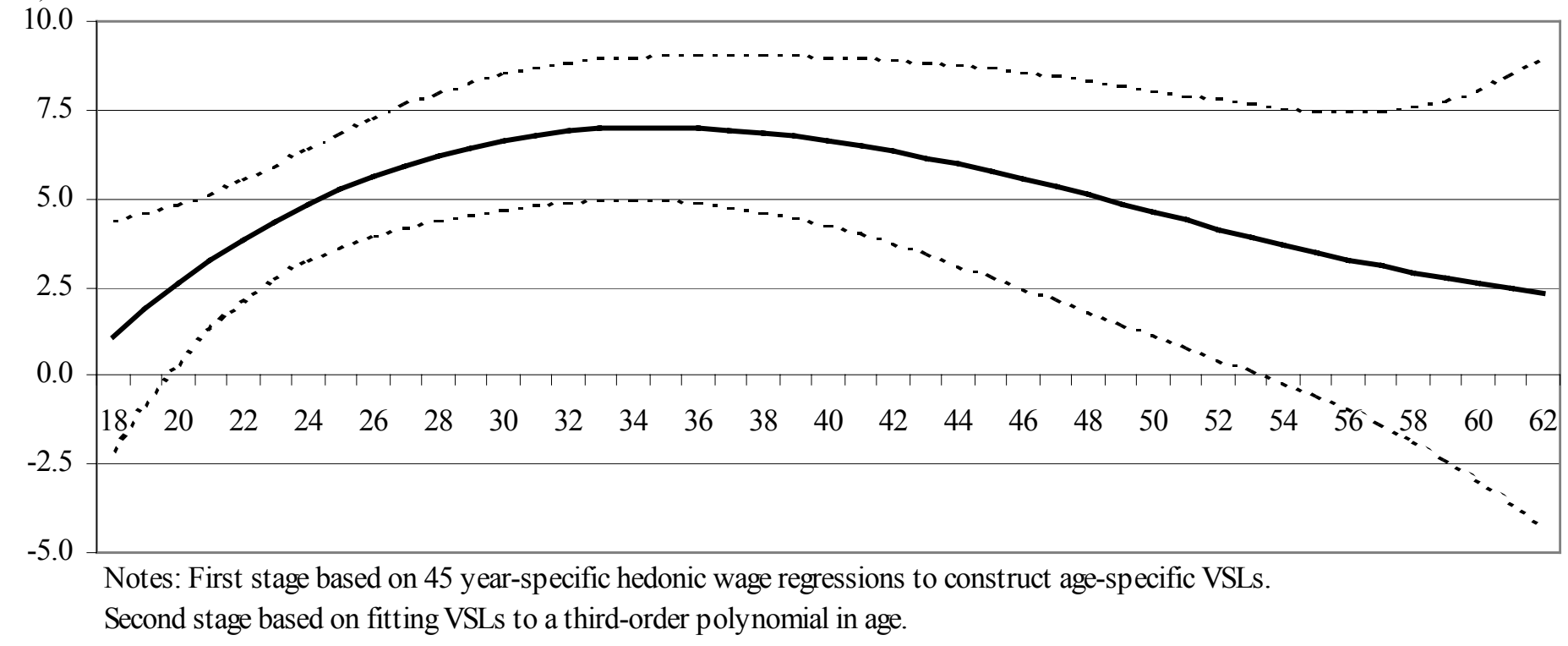


Figure 7. Age-Specific Value of Statistical Life Years

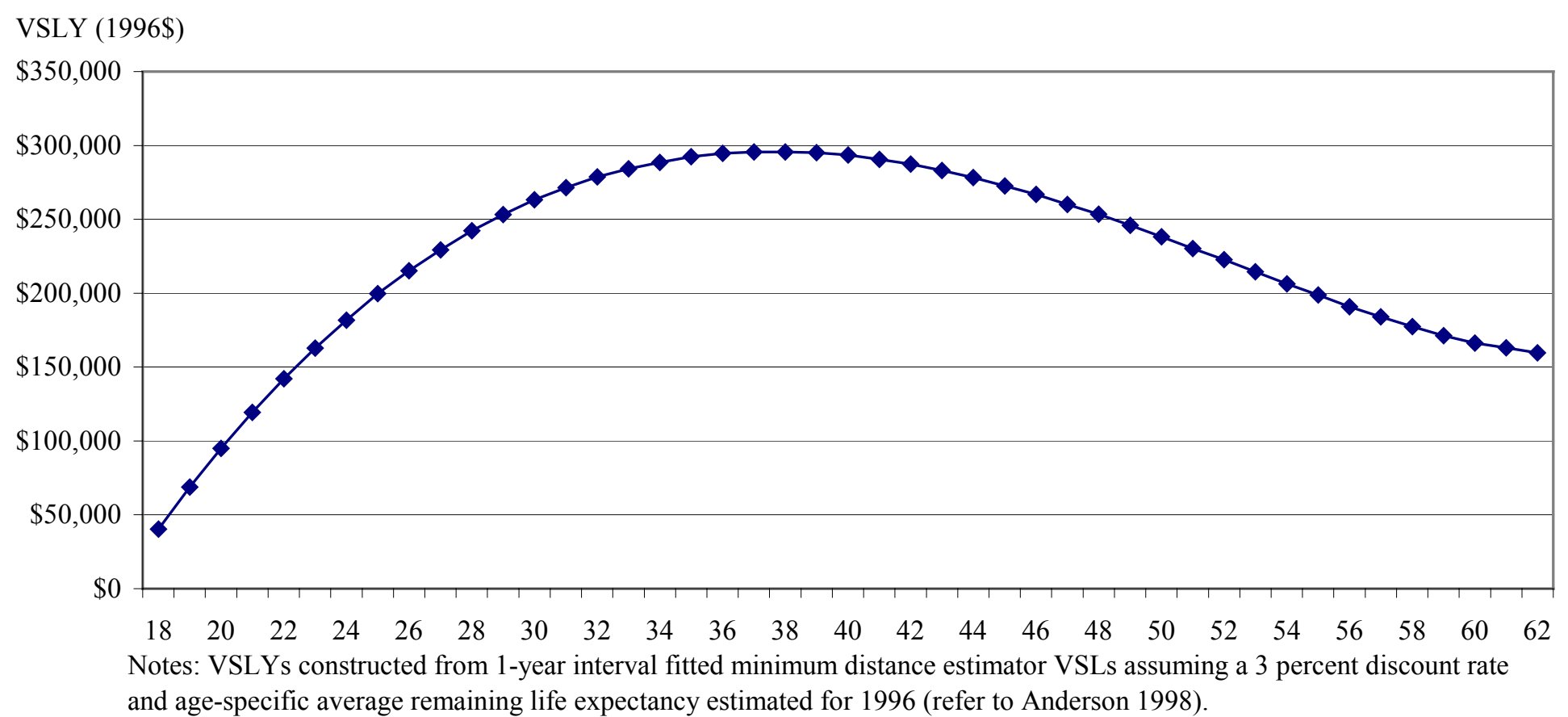

